\title{
Climate Modulation of North Atlantic Hurricane Tracks
}

\author{
JAMES P. KOSSIN \\ NOAA/National Climatic Data Center, Madison, Wisconsin \\ SUZANA J. CAMARGO \\ Lamont-Doherty Earth Observatory, Columbia University, Palisades, New York \\ MATTHEW SITKOWSKI \\ Cooperative Institute for Meteorological Satellite Studies, and Department of Atmospheric \\ and Oceanic Sciences, University of Wisconsin-Madison, Madison, Wisconsin
}

(Manuscript received 3 November 2009, in final form 26 January 2010)

\begin{abstract}
The variability of North Atlantic tropical storm and hurricane tracks, and its relationship to climate variability, is explored. Tracks from the North Atlantic hurricane database for the period 1950-2007 are objectively separated into four groups using a cluster technique that has been previously applied to tropical cyclones in other ocean basins. The four clusters form zonal and meridional separations of the tracks. The meridional separation largely captures the separation between tropical and more baroclinic systems, while the zonal separation segregates Gulf of Mexico and Cape Verde storms. General climatologies of the seasonality, intensity, landfall probability, and historical destructiveness of each cluster are documented, and relationships between cluster membership and climate variability across a broad spectrum of time scales are identified.

Composites, with respect to cluster membership, of sea surface temperature and other environmental fields show that regional and remote modes of climate variability modulate the cluster members in substantially differing ways and further demonstrate that factors such as El Niño-Southern Oscillation (ENSO), Atlantic meridional mode (AMM), North Atlantic Oscillation (NAO), and Madden-Julian oscillation (MJO) have varying intrabasin influences on North Atlantic tropical storms and hurricanes. Relationships with African easterly waves are also considered. The AMM and ENSO are found to most strongly modulate the deep tropical systems, while the MJO most strongly modulates Gulf of Mexico storms and the NAO most strongly modulates storms that form to the north and west of their Cape Verde counterparts and closer to the NAO centers of action.

Different clusters also contribute differently to the observed trends in North Atlantic storm frequency and may be related to intrabasin differences in sea surface temperature trends. Frequency trends are dominated by the deep tropical systems, which account for most of the major hurricanes and overall power dissipation. Contrarily, there are no discernable trends in the frequency of Gulf of Mexico storms, which account for the majority of landfalling storms. When the proportion that each cluster contributes to overall frequency is considered, there are clear shifts between the deep tropical systems and the more baroclinic systems. A shift toward proportionally more deep tropical systems began in the early to mid-1980s more than 10 years before the 1995 North Atlantic hurricane season, which is generally used to mark the beginning of the present period of heightened activity.
\end{abstract}

Corresponding author address: James Kossin, NOAA/NCDC, 1225 W. Dayton St., CIMSS/University of Wisconsin-Madison, Madison, WI 53706.

E-mail: james.kossin@noaa.gov

DOI: 10.1175/2010JCLI3497.1

(C) 2010 American Meteorological Society 


\section{Introduction}

North Atlantic hurricane variability is measured in a variety of ways. Changes in storm intensity, duration, frequency, genesis location, and track all contribute to this variability, and each of these metrics can be related to regional and remote climate variability. Changes in storm intensity can be considered within the context of potential intensity, which is controlled by the ambient thermodynamic conditions that storms move through (Emanuel 1986; Holland 1997). Within this framework, potential intensity influences the distribution of hurricane intensities by modulating the upper limit (Emanuel 2000; Wing et al. 2007). Similarly, tropical cyclogenesis occurrence can be related directly to ambient thermodynamic conditions (Gray 1968; McBride and Zehr 1981; DeMaria et al. 2001; Camargo et al. 2007a; Nolan et al. 2007).

In addition to the direct effects of changing the ambient thermodynamic state that the storms move through, climate variability also relates to hurricane activity through indirect pathways that affect basinwide circulation patterns (Kossin and Camargo 2009). For example, modes of variability such as the Atlantic meridional mode (AMM), El Niño-Southern Oscillation (ENSO), North Atlantic Oscillation (NAO), and Madden-Julian oscillation (MJO) have been shown to affect North Atlantic hurricane activity through changes in atmospheric steering currents and vertical wind shear, among other pathways (Goldenberg and Shapiro 1996; Maloney and Hartmann 2000; Elsner 2003, hereafter E03; Xie et al. 2005a,b; Kossin and Vimont 2007; Camargo et al. 2009; Klotzbach 2010). These modes affect hurricane genesis locations and track, which affect storm duration. This leads to another factor modulating hurricane intensity since storms that last longer also typically achieve greater intensities (Emanuel 2000; Kossin and Vimont 2007). Thus hurricane intensity is modulated directly by local ambient thermodynamic conditions and indirectly by broader-scale regional conditions. In addition to the more obvious importance of hurricane tracks as they relate to landfall occurrence, there is then also a critical need to better understand the controls of track in order to adequately assess how intensity changes as climate varies.

Here we analyze North Atlantic tropical storm and hurricane tracks with the goal of improving our understanding of how these tracks are modulated by local and remote climate factors. We first apply a statistical method (section 2) that separates the historical record of tracks into groups, or "clusters," and then each cluster is analyzed separately. A general climatology of the clusters is given in section 3. Of particular interest is how cluster membership varies in time and how this variation relates to climate variability. Sea surface temperature (SST) and other environmental fields, composited around cluster membership, reveal the broad climatic conditions associated with each cluster (section 4), and these relationships are then further quantified through application of Poisson models using climate indices as covariates.

\section{Data and clustering method}

Tropical storm and hurricane tracks are obtained from the hurricane database (HURDAT) maintained by the National Oceanic and Atmospheric Administration (NOAA) National Hurricane Center (Jarvinen et al. 1984). All analyses are performed for the 58-yr period 1950-2007 with the exception of those of section 3f, which extends the analyses to the period 1878-2007, and section $4 \mathrm{~d}(5)$, which is constrained to 1974-2007. Composite analyses of SST were performed using the monthly NOAA Extended Reconstructed SST version 3 (ERSST V3) product (Smith et al. 2008). All other regional composites were performed using the National Centers for Environmental Prediction-National Center for Atmospheric Research (NCEP-NCAR) reanalysis fields (Kalnay et al. 1996). The AMM and ENSO indices, which characterize the leading modes of coupled air-sea variability in the Atlantic and Pacific Oceans, respectively, were obtained from the NOAA Climate Prediction Center. Here we use the Niño $1+2$ index to represent ENSO variability. The NAO index - based on the sea level pressure difference between Gibraltar and Reykjavik, Iceland (Jones et al. 1997) —was obtained from the Climatic Research Unit at the University of East Anglia. The all-season real-time multivariate MJO index (Wheeler and Hendon 2004), which characterizes a 30-60-day oscillation of tropical wind and convection (Madden and Julian 1994), was obtained from the Center for Australian Weather and Climate Research.

The cluster technique used here builds a mixture of quadratic regression models, which are used to fit the geographical shape of historical tropical storm and hurricane tracks. The cluster technique is described in detail in Gaffney et al. (2007), which comprises an application to Atlantic extratropical cyclones, some simple examples, and a discussion of the advantages of the method. The technique has been applied to western North Pacific typhoon tracks (Camargo et al. 2007b,c), eastern North Pacific hurricane tracks (Camargo et al. 2008), and tropical cyclones affecting Fiji (Chand and Walsh 2009, 2010). A brief discussion of the technique is provided in the appendix.

\section{Climatology and variability of North Atlantic track clusters}

\section{a. Genesis and track}

We begin with a general climatology of Atlantic storm tracks in terms of cluster membership. Figure 1 shows 
Tracks
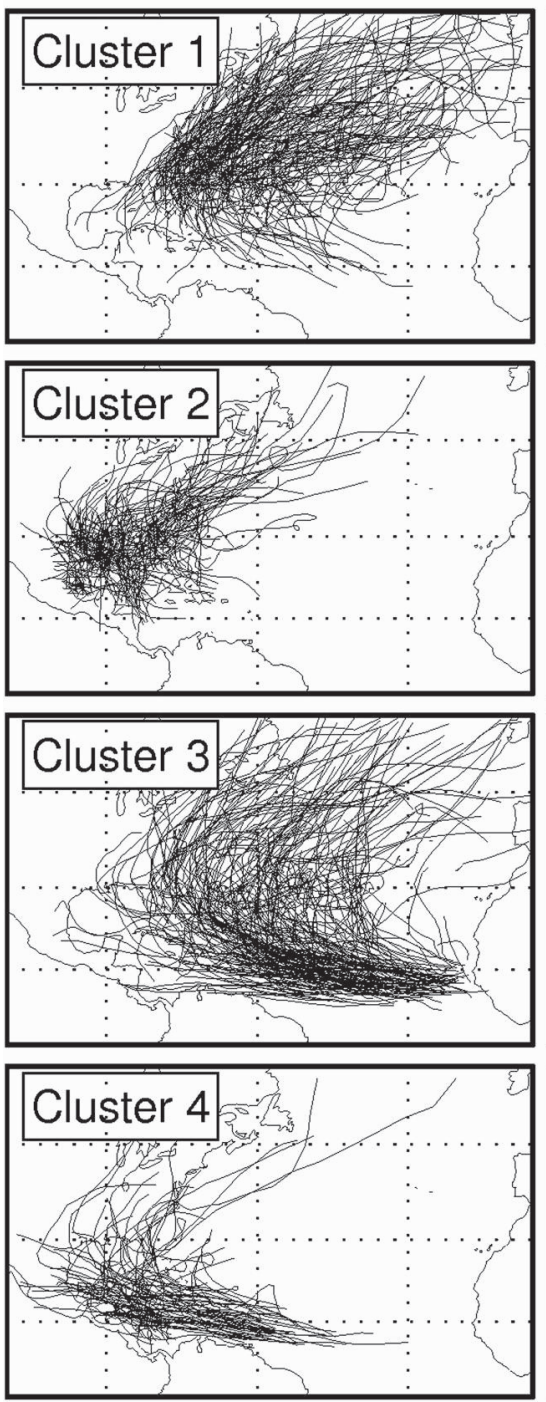

Genesis
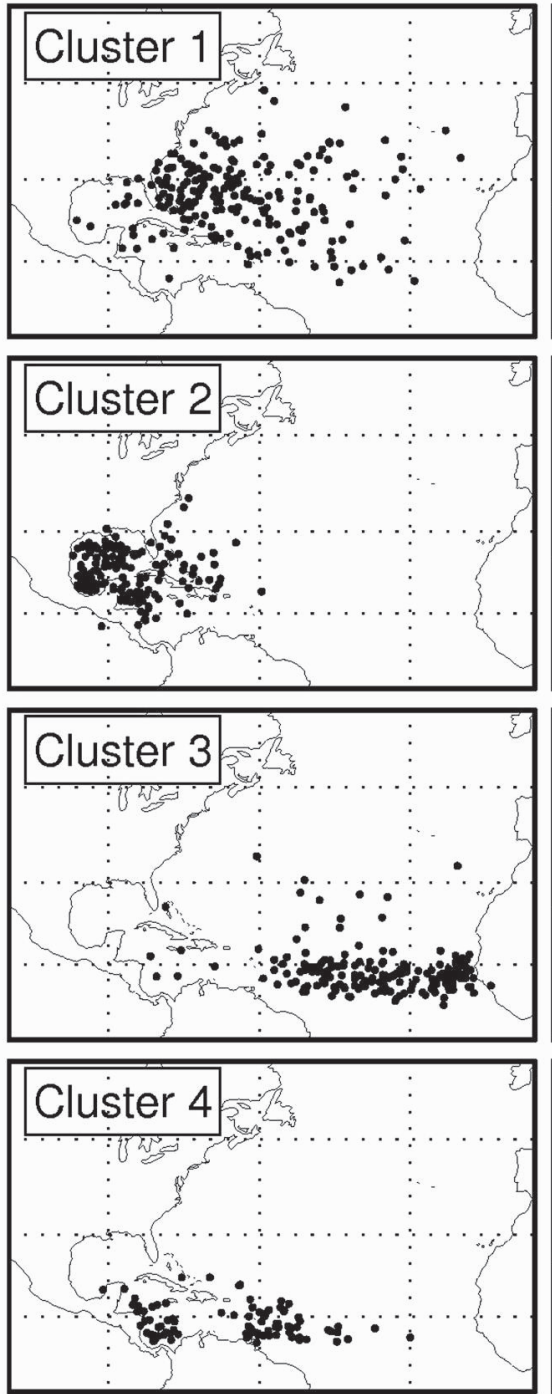

Landfall
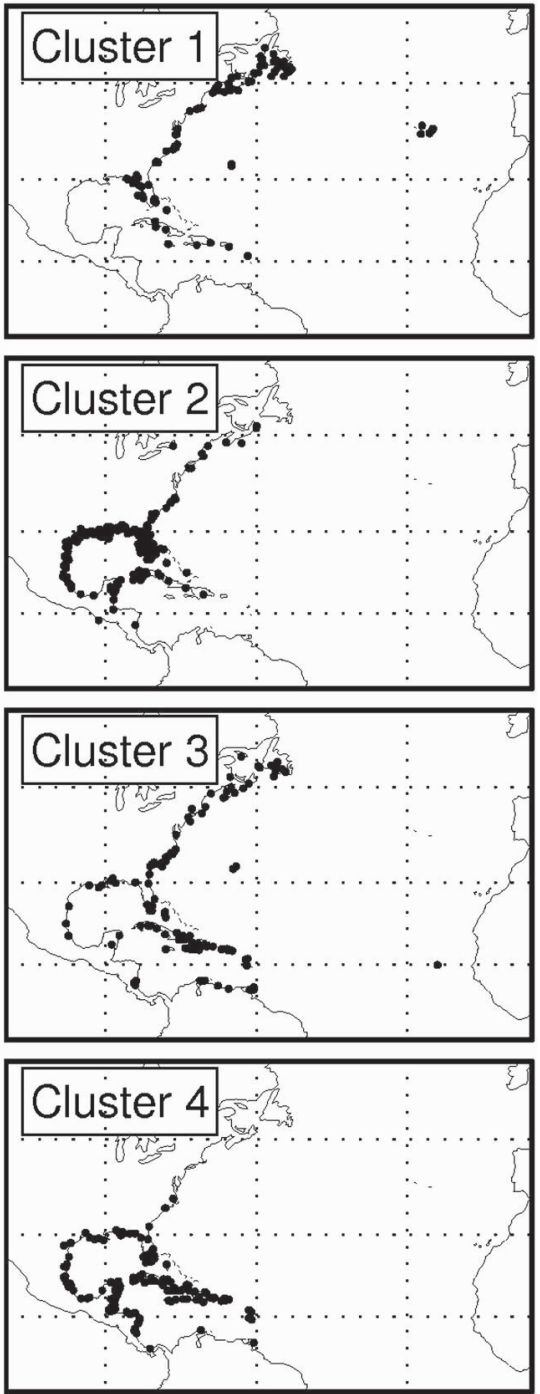

FIG. 1. North Atlantic tropical storm and hurricane tracks, genesis locations, and landfall locations during the period 1950-2007, as separated by the cluster analysis.

the separation of the historical tracks, genesis points, and landfall points between each of the four clusters and reveals a meridional and zonal separation between them. Storms in clusters 1 and 2 tend to form farther north than cluster 3 and 4 storms, and storms in clusters 1 and 3 tend to form farther east than cluster 2 and 4 storms. Cluster 2 storms form almost exclusively in the Gulf of Mexico and westernmost Caribbean and typically have a pronounced northward component in their tracks. Cluster 1 storms form farther east but also tend to have a pronounced northward track component. Essentially all classic "Cape Verde hurricanes"- such as Cleo (1958), Allen (1980), Gilbert (1988), and Ivan (2004) — are found in either cluster 3 or 4 , depending on their longitude of cyclogenesis. Compared with cluster 4 storms, which tend to maintain their primarily westward track until landfall, cluster 3 storms are more likely to "recurve," which describes the evolution of a storm track from westward and northward to eastward and northward (e.g., Hodanish and Gray 1993).

\section{b. Storm characteristics}

Table 1 summarizes various measures of activity for each of the four clusters shown in Fig. 1. Of the 623 tropical storms in the period 1950-2007, 356 are members of clusters 1 and 2 and 267 are classified within the more tropical systems of clusters 3 and 4 . A significantly larger proportion of cluster 3 and 4 storms intensify to 
TABLE 1. Comparison of various measures by cluster. Percent values (in parentheses) represent the proportions, within each cluster, of total storm counts that reached a given intensity at some point in its lifetime, or made landfall at least once.

\begin{tabular}{|c|c|c|c|c|}
\hline $1950-2007$ & Cluster 1 & Cluster 2 & Cluster 3 & Cluster 4 \\
\hline Storm count & 203 & 153 & 183 & 84 \\
\hline Hurricane count & $112(55 \%)$ & $70(46 \%)$ & $125(68 \%)$ & $55(65 \%)$ \\
\hline Category 2 hurricane count & $49(24 \%)$ & $29(19 \%)$ & $96(52 \%)$ & $41(49 \%)$ \\
\hline Category 3 hurricane count & $25(12 \%)$ & $19(12 \%)$ & $75(41 \%)$ & $35(42 \%)$ \\
\hline Category 4 hurricane count & $7(3 \%)$ & $11(7 \%)$ & $43(23 \%)$ & $21(25 \%)$ \\
\hline Category 5 hurricane count & $0(0 \%)$ & $5(3 \%)$ & $11(6 \%)$ & $10(12 \%)$ \\
\hline Mean LMI per storm $\left(\mathrm{m} \mathrm{s}^{-1}\right)$ & 35 & 35 & 44 & 45 \\
\hline Mean duration per storm (days) & 4.9 & 3.3 & 8.3 & 5.4 \\
\hline Mean PDI per storm $\left(10^{10} \mathrm{~m}^{3} \mathrm{~s}^{-2}\right)$ & 1.5 & 1.1 & 4.6 & 3.0 \\
\hline Total PDI $\left(10^{10} \mathrm{~m}^{3} \mathrm{~s}^{-2}\right)$ & 297 & 173 & 839 & 249 \\
\hline Landfalling storm count & $68(33 \%)$ & $140(92 \%)$ & $53(29 \%)$ & $73(87 \%)$ \\
\hline Total number of landfall events & 86 & 205 & 114 & 157 \\
\hline Mean intensity at landfall $\left(\mathrm{m} \mathrm{s}^{-1}\right)$ & 24 & 25 & 34 & 31 \\
\hline
\end{tabular}

hurricane strength because of their longer duration ${ }^{1}$ over warm tropical SSTs and through climatologically low vertical wind shear. The mean lifetime-maximum intensity (LMI) achieved by cluster 3 and 4 members is $\sim 45 \mathrm{~m} \mathrm{~s}^{-1}$, while cluster 1 and 2 storms achieve only $35 \mathrm{~m} \mathrm{~s}^{-1}$ on average. Although the frequency of cluster 3 and 4 storms is less than cluster 1 and 2 storms, their increased duration and intensity substantially influences their contribution to the total power dissipation index (PDI) (Emanuel 2005). The total PDI for the 58-yr period is dominated by the more tropical systems by a factor greater than 2. Storms that have been objectively classified as "baroclinically enhanced" (Hess et al. 1995; Elsner et al. 1996; Elsner and Kara 1999) comprise 47, 22,2 , and 2 members of clusters $1,2,3$, and 4 , respectively. This is consistent with the notion that cluster 1 and 2 storms are more often interacting with (and drawing energy from) a baroclinic environment than their more tropical counterparts.

The number of storms that intensify to become major hurricanes (Saffir-Simpson Category 3-5) is also substantially weighted toward the more tropical systems of clusters 3 and 4 . On average $41 \%-42 \%$ of these storms become major hurricanes, compared to only $12 \%$ of their higher-latitude counterparts. Of the 26 Category 5 hurricanes that have been observed in the past 58 years, 21 are classified in clusters 3 and 4, and there is better than a one-in-ten chance that a member of cluster 4 will reach this uppermost intensity category. Although there are considerably fewer storms classified as cluster 4 storms compared to their cluster 3 counterparts, and the tracks and duration of cluster 4 storms are generally shorter, the total number of Category 5 hurricanes is

\footnotetext{
${ }^{1}$ Duration is defined here as the time period between the first and last instance of tropical storm strength wind $\left(17 \mathrm{~m} \mathrm{~s}^{-1}\right)$.
}

roughly equivalent in both groups. This is due to the more southern tracks of cluster 4, which share some characteristics with the "straight moving" hurricanes described by E03 as hurricanes that tend to track due westward and threaten the Caribbean and North America south of around $35^{\circ} \mathrm{N}$. These storms tend to track through regions of anomalously high potential intensity for extended periods of time that allow them to reach intensities that are close to this enhanced potential (Kossin and Vimont 2007). This observation emphasizes the important combined direct and indirect roles of local thermodynamics and track, respectively, in modulating North Atlantic hurricane intensity.

\section{c. Landfall}

In addition to variations in frequency, duration, and intensity, the different cluster members exhibit markedly different landfall behaviors (Fig. 1; Table 1). Here a landfall event is identified when a storm center moves onto land. To capture landfall on small islands, the 6-hourly HURDAT positions were interpolated to 15 -min resolution using cubic splines. Of the 203 cluster 1 storms, 68 (33\%) made landfall at least once, mostly along the U.S. and Canada East Coast. The genesis locations of cluster 2 storms are largely confined to the Gulf of Mexico and western Caribbean, and 92\% (140 out of 153) of these storms struck land at least once, mostly along the coasts of the U.S. Gulf States, Yucatan, and Greater Antilles. The genesis locations and landfall intensities of cluster 3 storms are markedly different from cluster 1 storms, but they exhibit qualitatively similar landfall patterns and proportions. About 29\% (53 out of 183) made landfall at least once, mostly along the U.S. and Canada East Coast, often after earlier landfalls in the Antilles. The total number of cluster 4 storms is relatively low compared to the other clusters, but most $(87 \%$, or 73 out of 84$)$ struck land at least once 


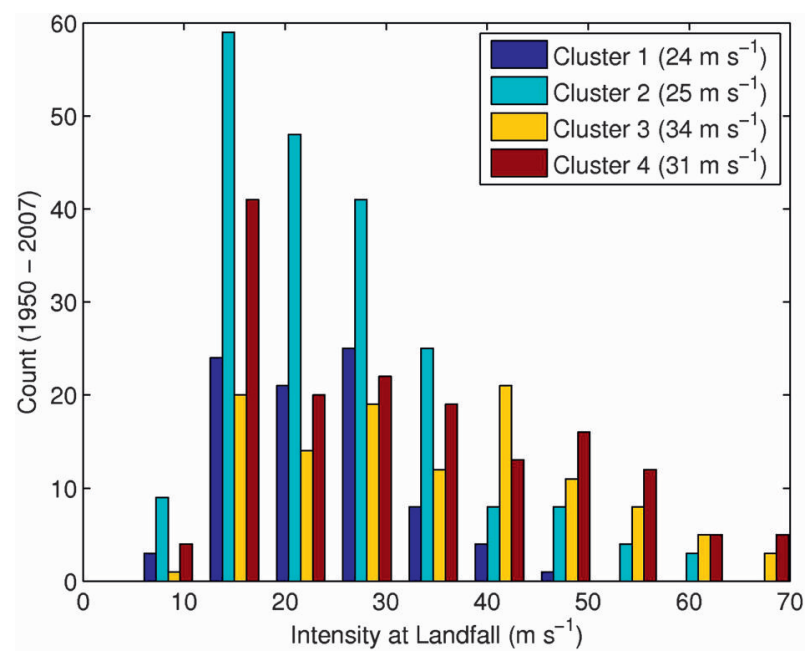

FIG. 2. Distributions of intensity at landfall for each cluster. The mean landfall intensity is shown in parentheses. Note that the distributions comprise multiple landfall events among individual storms.

owing to their relatively straight westward track. Most of these landfalls occur in the Antilles and along the Mexico and Central America coast. When multiple landfalls of individual storms are counted, it is evident (Table 1) that cluster 3 and 4 storms (and to a lesser extent, cluster 2 storms) have a much greater tendency toward multiple land strikes than cluster 1 storms. Most notably, the centers of the 84 cluster 4 storms struck land a total of 157 times, while the 203 cluster 1 storms struck land a total of 86 times.

The distribution of intensities at landfall ${ }^{2}$ for each cluster is shown in Fig. 2, and Table 2 shows the most destructive U.S. landfalling hurricanes separated by cluster. Cluster 2 storms are most likely to move onto land at relatively low intensities, but landfalls are observed within a broad spectrum of intensities and very intense and destructive landfalls have occurred. Landfall intensities of cluster 3 and 4 storms are more flatly distributed and have been observed at all intensities within the overall distribution. Despite the similarity between the landfall patterns of clusters 1 and 3 (Fig. 1), they differ greatly in their intensities at landfall and their historical destructiveness. The mean landfall intensity of cluster 1 storms is $24 \mathrm{~m} \mathrm{~s}^{-1}$ compared to $34 \mathrm{~m} \mathrm{~s}^{-1}$ for cluster 3 storms, and there is no case of a cluster 1 storm

\footnotetext{
${ }^{2}$ Here, landfall intensities are linearly interpolated from neighboring 6-hourly HURDAT values and can be significantly weaker than the maximum intensities experienced at the landfall locations. Actual maximum intensities during landfall events also typically occur prior to the center moving onshore, as the maximum winds are located away from the center.
}

TABLE 2. Cluster membership of the most destructive hurricanes in the period 1950-2005. Some notable hurricanes that occurred prior to 1950 are listed parenthetically (Blake et al. 2007).

\begin{tabular}{cl}
\hline \hline Cluster & \multicolumn{1}{c}{ Most destructive hurricanes } \\
\hline 1 & Bob 1991 \\
2 & Carol 1954, Audrey 1957, Camille 1969, Celia 1970, \\
& Agnes 1972, Alicia 1983, Elena 1985, Juan 1985, \\
& Erin 1995, Opal 1995, Katrina 2005, Rita 2005 \\
& (Labor Day Hurricane 1935, Great Atlantic \\
& Hurricane 1944) \\
& Hazel 1954, Connie 1955, Diane 1955, Donna \\
& 1960, Dora 1964, Betsy 1965, Beulah 1967, David \\
& 1979, Frederic 1979, Gloria 1985, Hugo 1989, \\
& Andrew 1992, Marilyn 1995, Fran 1996, Georges \\
& 1998, Floyd 1999, Isabel 2003, Frances 2004, Ivan \\
& 2004 (Texas Hurricane 1915, New England \\
& Hurricane 1938) \\
& King 1950, Carla 1961, Cleo 1964, Eloise 1975, Lili \\
& 2002, Charley 2004, Jeanne 2004, Wilma 2005 \\
& (Galveston Hurricane 1900, Florida Hurricane \\
& 1926)
\end{tabular}

with landfall intensity greater than $45 \mathrm{~m} \mathrm{~s}^{-1}$. From Tables 1 and 2 it is seen that $10 \%$ (19 of 183) of the cluster 3 storms during 1950-2007 are categorized with the most destructive hurricanes in that period compared to $0.5 \%$ ( 1 of 203 ) of cluster 1 storms.

\section{d. Seasonality}

The seasonality of cluster membership is shown in Fig. 3. As expected (e.g., Davis and Bosart 2003; McTaggart-Cowan et al. 2008), the higher-latitude storms of cluster 1 are proportionally more prevalent during the early and late parts of the hurricane season. During these periods, thermodynamic conditions in the tropics are generally less favorable for cyclogenesis, but higher-latitude conditions are favorable for baroclinic initiation of storms that can subsequently transition to warm-core tropical cyclones. During May-July cluster 2 storms in the Gulf of Mexico are the most prevalent, while during October-December cluster 1 storms occur most frequently. Initiation of cluster 2 storms in the Gulf of Mexico can often be traced to "sagging fronts," a colloquial term sometimes used by forecasters to describe midlatitude frontal systems that deviate southward into the gulf and provide the baroclinic conditions that are favorable for cyclogenesis (see also Bracken and Bosart 2000). These events are more common in boreal spring and a secondary local maximum in frequency of occurrence of cluster 2 storms is observed in June.

Cluster 3 storms are observed mostly during the peak months of the hurricane season (August-September) and their distribution has a large degree of kurtosis; that is, they occur mostly within a narrow time period. 

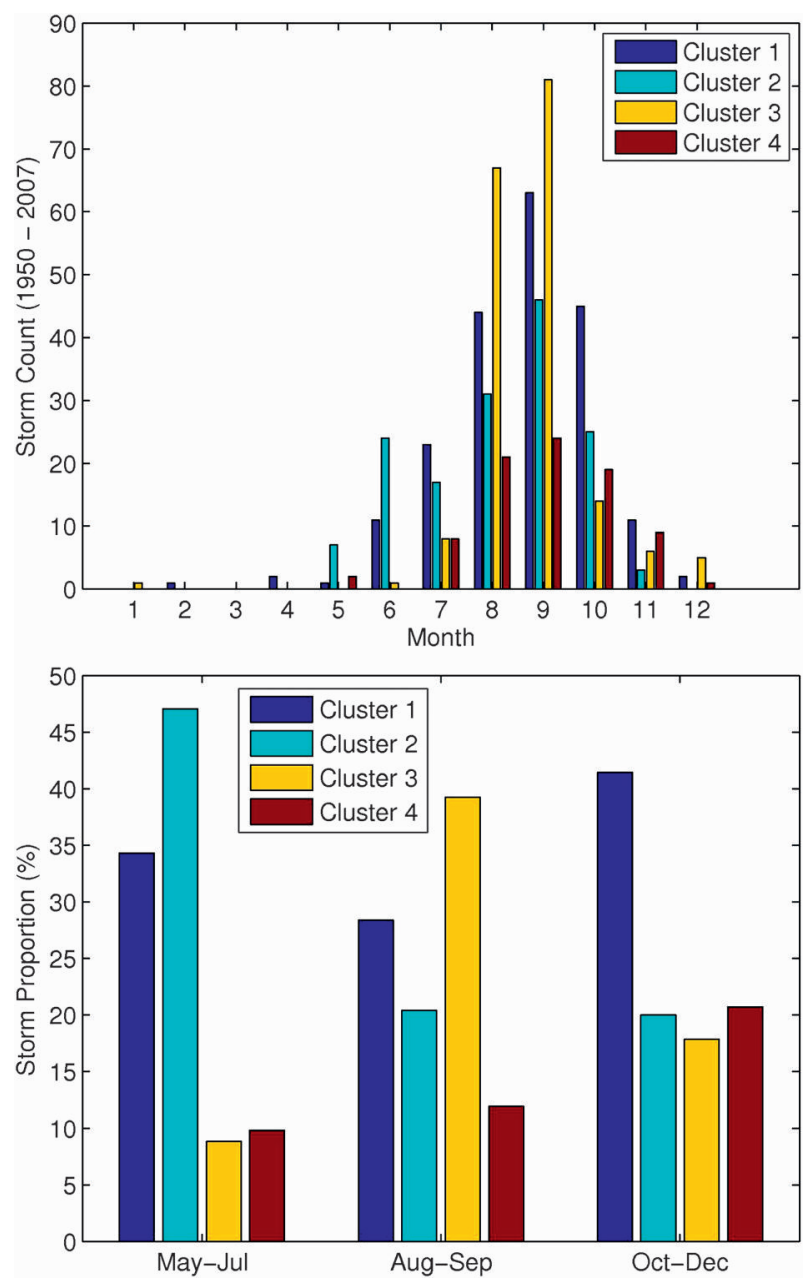

FIG. 3. Seasonality of cluster membership: (top) total storm count for the period 1950-2007 for each cluster as a function of month and (bottom) contribution of each cluster to the total number of storms during the early (May-July), middle (AugustSeptember), and late (October-December) parts of the hurricane season.

Cluster 1 and 4 storms have broader seasonal distributions and cluster 2 storms have a broader distribution that is also bimodal with maxima in June and September. In terms of the proportion of total storms, cluster 2 storms dominate in the early part of the season, cluster 3 storms dominate during the height of the season, and cluster 1 storms dominate in the late part of the season.

In addition to the seasonality of the thermodynamic conditions of the tropical Atlantic, another likely factor controlling the seasonal intercluster distributions is the seasonality of the number of easterly waves emerging from the west coast of Africa (discussed further in section $4 \mathrm{c}$ ). These waves often serve as progenitors of cyclogenesis in the deep tropics and thus would be expected to most strongly modulate clusters 3 and 4 . The seasonal distribution of easterly wave counts has a peak during August-September and roughly aligns with the broader seasonal cycle of total storm counts (e.g., Thorncroft and Hodges 2001, their Fig. 11). However, the kurtosis of the cluster 3 and, to a lesser extent, cluster 4 seasonal distributions suggests that thermodynamic conditions play the dominant role in suppressing earlyand late-season cluster 3 and 4 genesis, rather than reduced numbers of easterly waves. For example, the average number of easterly waves in June is still about $60 \%-70 \%$ of the maximum number occurring on average in September, but cluster 3 and 4 storms are extremely rare in June.

\section{e. Interannual variability and trends}

Time series of annual frequency of cluster membership are shown in Fig. 4. In addition to the observed interannual variability, application of a 5-yr moving-average filter reveals variability on decadal time scales with relatively more frequent cluster 1 storms and less frequent cluster 3 storms during the 1970s and 1980s. The welldocumented increases of frequency in the latter part of the record (e.g., Kossin and Vimont 2007, their Fig. 1) are also evident, to varying degrees, in the frequency of each cluster. This will be explored further below.

When the percentage that each cluster contributes to the total storm rate is considered (Fig. 5), an interesting picture emerges. As the total annual rate has increased, there has been a clear regime shift, beginning in the early to mid-1980s, toward a greater proportion of cluster 3 and 4 storms and a concurrent shift toward proportionally fewer cluster 1 and 2 storms. This is suggestive that the apparent shift toward proportionally more "tropical only" hurricanes and proportionally fewer baroclinically initiated or enhanced hurricanes, as described by Kimberlain and Elsner (1998), may have begun earlier than the 1995 hurricane season. That is, while the 1995 season is often used to mark the beginning of the present period of heightened activity (e.g., Goldenberg et al. 2001), the shift in relative proportions of higher- and lower-latitude storms appears to have begun more than 10 years prior to this. Identifying the environmental changes that may be associated with these shifts is the subject of section 4 .

The early- to mid-1980s regime shift, seen in Fig. 5, takes place within the period of regular operational polar-orbiting and geostationary satellite observations ${ }^{3}$

\footnotetext{
${ }^{3}$ The first fully operational polar-orbiting meteorological satellite (TIROS-10) was launched in July 1965. The launch of the second Geostationary Operational Environmental Satellite (GOES-2) in June 1977 marked the beginning of regular operational geostationary satellite observations in the North Atlantic.
} 

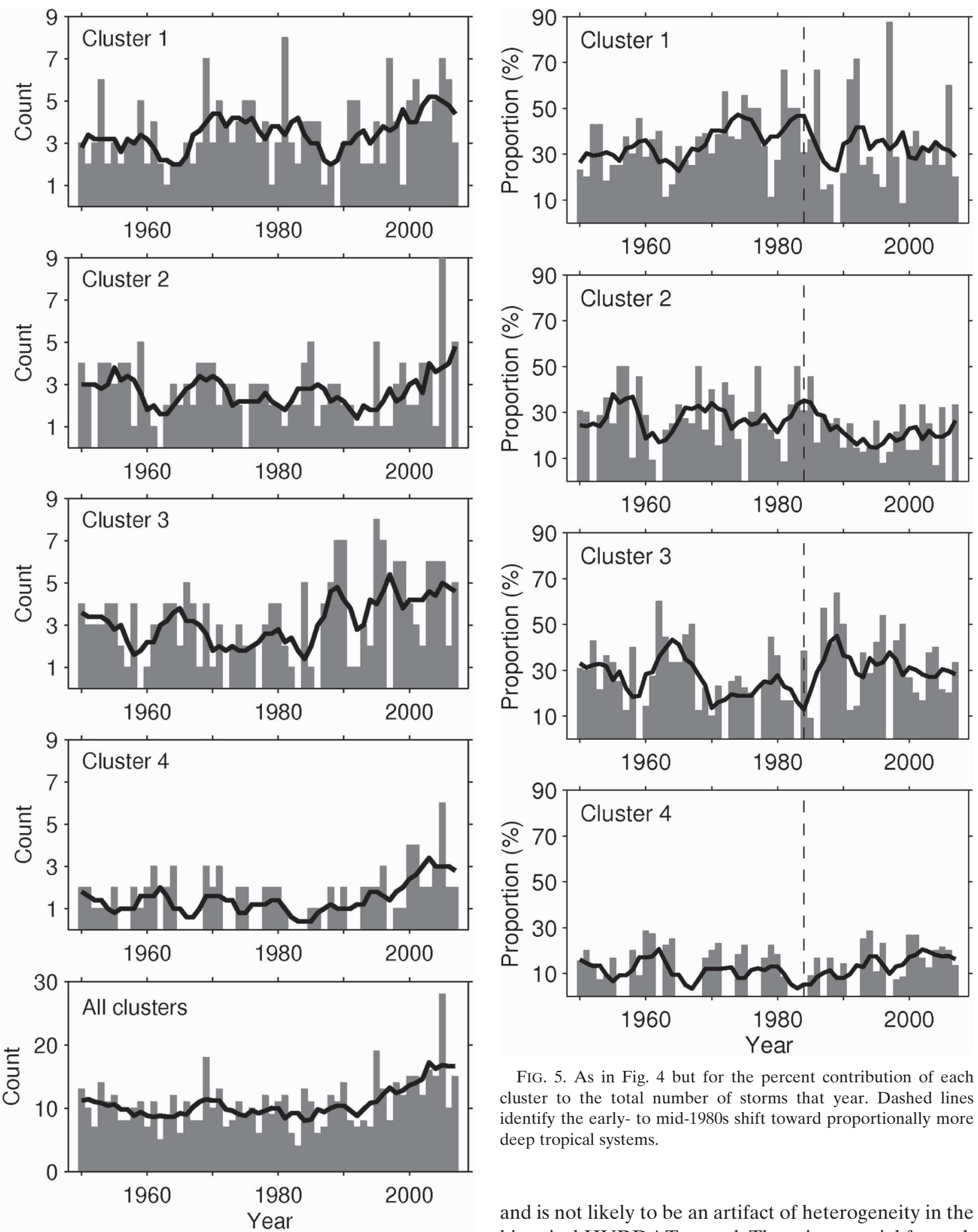

FIG. 4. Annual storm counts for each cluster. The bold line shows the time series filtered with a centered 5-yr moving window.

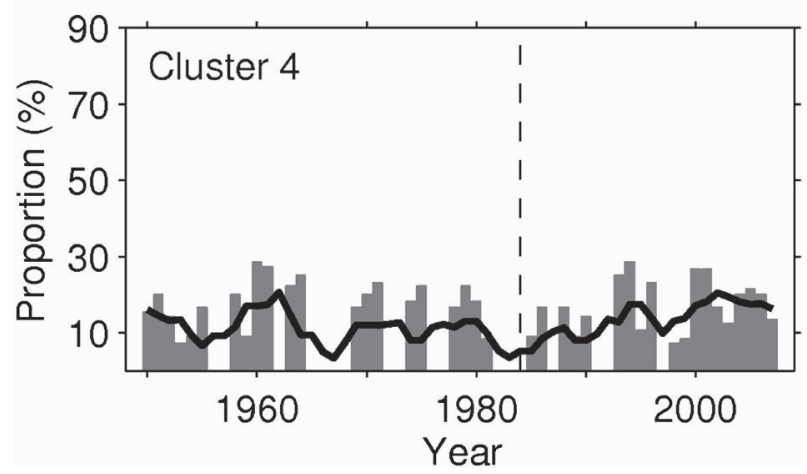

FIG. 5. As in Fig. 4 but for the percent contribution of each cluster to the total number of storms that year. Dashed lines identify the early- to mid-1980s shift toward proportionally more deep tropical systems.

and is not likely to be an artifact of heterogeneity in the historical HURDAT record. There is potential for such artifacts in records of storm frequency that comprise a combination of pre- and postsatellite era observations, particularly when considering the frequency of storms 
TABLE 3. Poisson regression of annual North Atlantic storm rate (for each cluster) onto year. Rates are for the period 1950-2007. The covariate (Year) is standardized.

\begin{tabular}{llccrc}
\hline \hline & & & Std & $z$ & \\
& & Estimate & error & value & $\operatorname{Pr}(>|z|)$ \\
\hline Cluster 1 & (Intercept) & 1.2454 & 0.0707 & 17.62 & 0.0000 \\
& Year & 0.1222 & 0.0711 & 1.72 & 0.0857 \\
Cluster 2 & (Intercept) & 0.9699 & 0.0809 & 12.00 & 0.0000 \\
& Year & 0.0132 & 0.0816 & 0.16 & 0.8715 \\
Cluster 3 & (Intercept) & 1.1327 & 0.0751 & 15.08 & 0.0000 \\
& Year & 0.1828 & 0.0753 & 2.43 & 0.0152 \\
Cluster 4 & (Intercept) & 0.3419 & 0.1122 & 3.05 & 0.0023 \\
& Year & 0.2416 & 0.1120 & 2.16 & 0.0309 \\
& & & & & \\
All clusters & (Intercept) & 2.3660 & 0.0404 & 58.58 & 0.0000 \\
& Year & 0.1289 & 0.0406 & 3.17 & 0.0015 \\
\hline
\end{tabular}

that form in the far eastern Atlantic where presatellite era observations can be sparse (Landsea 2007; Vecchi and Knutson 2008). It is of interest then that the proportion of cluster 3 storms, which comprise almost all of these far east storms, enters a 10-15-yr period of low proportion concurrent with the mid-1960s start of the polar-orbiting satellite era and remains in this low regime within the geostationary satellite era until transitioning to the present high proportion regime in the 1980s. While the potential for data heterogeneity issues cannot be completely ruled out, there is no clear evidence in the time series shown in Figs. 4-5 that presatellite era storms were systematically missed in the far eastern North Atlantic after the post-World War II return to active North Atlantic shipping-lane traffic and the introduction of aircraft reconnaissance into hurricanes.

Since the annual tropical storm rates shown in Fig. 4 are more naturally modeled as a Poisson process (E03; Elsner and Schmertmann 1993), an ordinary least squares linear analysis is not an optimal choice for exploring trends in these time series. As a natural alternative, we perform Poisson regressions with time (Year) as the covariate, the details of which are shown in Table 3. Here the expected annual rate is given by $\lambda=\exp \left(a_{0}+a_{1} x\right)$, where the covariate $x$ is year, and the coefficients $a_{0}$ and $a_{1}$, shown in Table 3 , are deduced by maximum likelihood estimation. It should be noted that our 58-yr sample of annual rates is overdispersed (i.e., the variance exceeds the mean), and the assumption of a Poisson distribution may itself not be optimal. An alternative distribution is the more general negative binomial distribution, which is also sometimes employed in hurricane risk models (e.g., Vickery et al. 2000). All analyses in this section and section $4 \mathrm{~d}$ were repeated with a negative binomial model, but goodness-of-fit tests did not identify significant differences between assuming a Poisson versus negative binomial distribution, and the model results were nearly

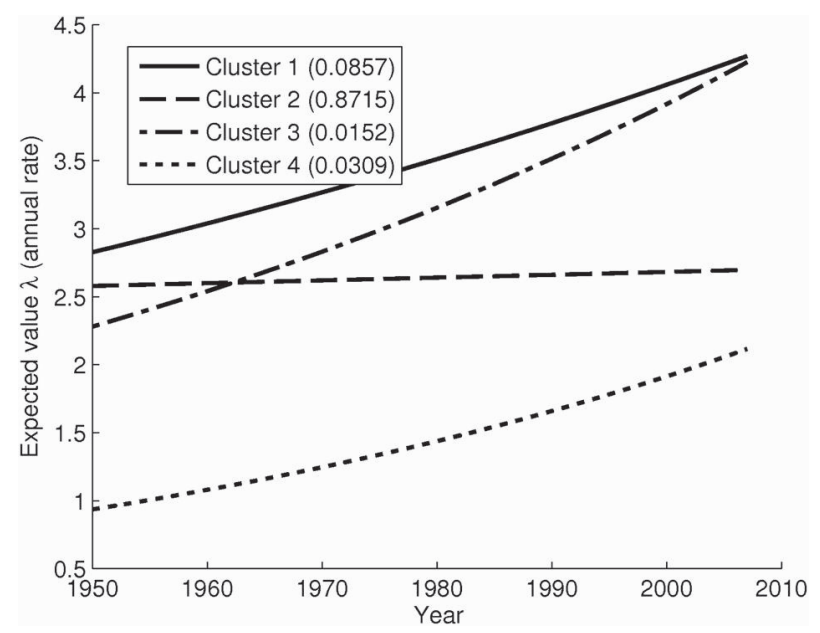

FIG. 6. Expected annual rate, for each cluster, as a function of year. The expected rates are based on a Poisson regression of storm rate onto year. The $p$ value associated with each regression is shown in parentheses.

identical in all cases. In the interest of parsimony, the Poisson model is used here.

The nonlinear relationship between expected annual rate $(\lambda)$ and year is shown in Fig. 6 for each cluster. An increase is noted in cluster 1 rates, but confidence that this trend is nonzero is less than $95 \%$ ( $p$ value of 0.0857 in Table 2), and the expected rates of cluster 2 storms have remained essentially fixed. Rates of cluster 3 and 4 storms, however, have been significantly increasing and both exhibit a doubling within the 58-yr period (with confidence levels greater than $95 \%$ ). The marked increase in cluster 3 storms is particularly noteworthy as this cluster has historically comprised the majority of the most destructive U.S. landfalling hurricanes (Table 2) and their total power dissipation is greater than the combined total power dissipation of the remaining three clusters (Table 1).

The trends, or lack of trends, observed in the genesis rates within each cluster can be at least partly reconciled in terms of regional SST trends (Fig. 7). Clusters 3 and 4, whose main formation regions are collocated with regions that have experienced upward SST trends, are also exhibiting the greatest upward trends in annual rate. In comparison, the main genesis region of cluster 2 is collocated with a region that is experiencing no upward SST trend (or a weak cooling trend). The main genesis region of cluster 1 storms spans regions of both warming and cooling trends in SST, and the overall trend is positive but significantly weaker than those found in clusters 3 and 4 .

When considered by individual clusters, the welldocumented increase in North Atlantic hurricanes since 1950, which is also clearly evident in Table 3 (indicated by "All clusters"), is thus largely confined to increases in the deep tropical systems of clusters 3 and 4 , which form 

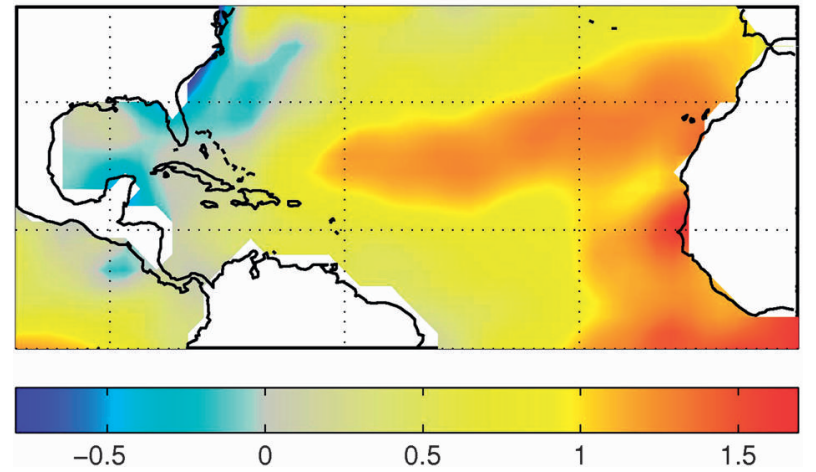

FIG. 7. Observed SST trends $\left({ }^{\circ} \mathrm{C}\right.$ century $\left.{ }^{-1}\right)$ during the official North Atlantic hurricane season (June-November) for the period 1950-2007.

over regions of positive SST trends. Recalling that the majority of long-lived major hurricanes are members of clusters 3 and 4 (Table 1), this helps to explain the dramatic increases in annual North Atlantic hurricane power dissipation and frequency of Category 4-5 storms that have been observed in the past few decades, and their relationship with SST (Emanuel 2005; Webster et al. 2005). In section 4, we will show that the welldocumented relationships between storm rates and climate variability are also highly variable among the different clusters.

\section{f. Short-duration storms}

Recently, Landsea et al. (2010) showed that a large contribution of the observed trend in the HURDAT record (from 1878 to present) of North Atlantic tropical storm and hurricane frequency is due to a trend in the frequency of short-lived storms. From this, they hypothesized that the long-term frequency trends in HURDAT may be spuriously introduced through human advances in technology and analysis methods by arguing that detection of short-lived storms is particularly sensitive to these advances. Following their analysis, we considered the frequency of storms with duration equal to or less than 2 days in the HURDAT, extending our analyses to the period 1878-2007 and separating these cases by their cluster membership to better identify intrabasin aspects.

The time series of short-duration cluster 1 and 3 annual storm counts (Figs. 8a,c) support the idea that short-lived storms over open water in the eastern North Atlantic were difficult to detect prior to the introduction of aircraft reconnaissance in the 1940s and satellite observations in the 1960s (cf. Vecchi and Knutson 2008, their Fig. 6). For example, there were no short-lived cluster 3 storms detected prior to the 1960s (Fig. 8c), while these short-lived storms have typically made up a substantial (as high as $50 \%$ ) proportion of cluster 3 storms during the satellite era (Fig. 8i). Cluster 4 storms (Fig. 8d) track through a region where it is less likely that presatellite era short-lived storms would go undetected, which is supported by the more weakly defined upward jump in counts in the 1960s compared with the more open-water systems of clusters 1 and 3 .

Cluster 2 storms are the most likely to be short lived (Fig. 8h) because of the constrained spatial area of the Gulf of Mexico, and they have comparatively short duration on average (Table 1). Because of their proximity to land and the relatively low probability of nondetection in that region (as described by Vecchi and Knutson 2008), it was somewhat unexpected that the time series of short-duration cluster 2 storm counts (Fig. 8b) would exhibit heterogeneity comparable to the more remote storms of clusters 1 and 3 . In fact, the trend in shortduration cluster 2 storms is comparable to the trend in all short-duration storms in the remaining clusters (Figs. 8e,f), and the trends described by Landsea et al. (2010) are influenced as much by Gulf of Mexico storms as by storms over more open water and in the eastern North Atlantic. This is suggestive that the trend identified by Landsea et al. may be partly due to physical processes and not entirely to data heterogeneity. This is further supported by the recent analysis of Emanuel (2010), which demonstrated that synthetic storm tracks generated by downscaling environmental reanalysis fields also contain an upward trend in short-duration storms. The trend found by Emanuel is independent of the HURDAT record and its inherent heterogeneity. Thus there is evidence that both physical processes and data heterogeneity contribute to the observed trends in short-duration storms, although the relative contribution of each remains uncertain.

\section{Relationships between track and climate variability}

\section{a. Sea surface temperature}

To identify environmental conditions associated with tropical cyclogenesis and track within each cluster, we first considered SST anomalies composited around cluster membership (Fig. 9). Anomalies represent local deviation from the monthly mean, and the month is chosen based on the genesis date of each cluster member. The anomalies are standardized to accommodate the greater variance in the early and late parts of the hurricane season and the regional variance differences between the Pacific and Atlantic. This was done by dividing the monthly anomaly at each position by the standard deviation of SST for that month at that position (based on 1950-2007). 

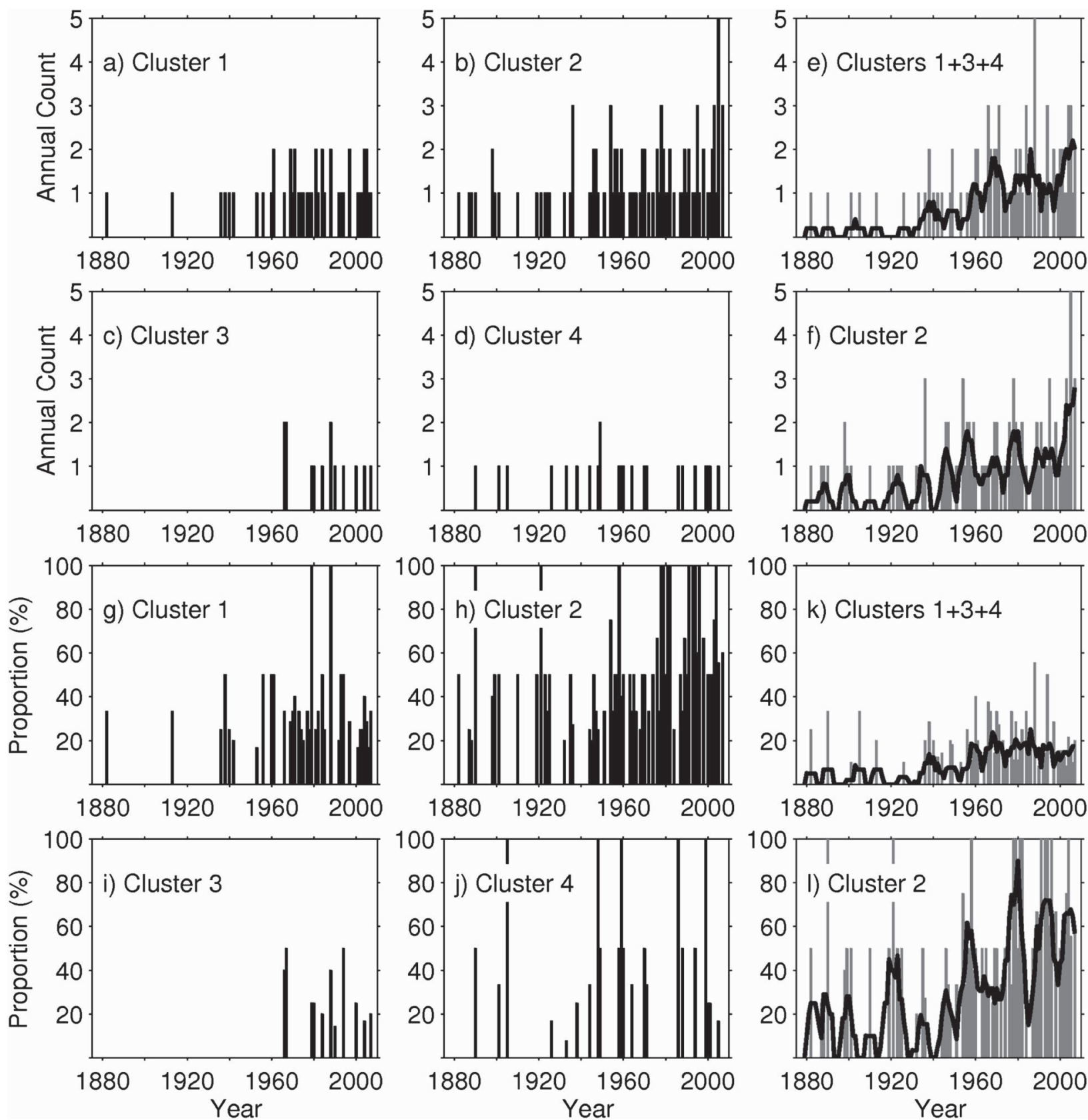

FIG. 8. (a)-(d) Time series of annual short-duration storm counts. (e),(f) Short-duration cluster 2 counts compared with the combined counts of the remaining clusters. (g)-(l) As in (a)-(f), but for the percent contribution of short-duration storms to the total annual storm counts. Short-duration storms maintain an intensity of $35 \mathrm{kt}\left(17 \mathrm{~m} \mathrm{~s}^{-1}\right)$ or greater for two days or less. Much of the trend in short-duration storms is found in cluster 2, which largely comprises storms in the Gulf of Mexico.

\section{b. Coupled air-sea climate modes}

The SST anomaly field associated with cluster 1 is relatively devoid of features, suggesting that members of this cluster are not strongly controlled by anomalous local, regional, or remote low-level temperature structure. There is a weak signature of an enhanced meridional
SST gradient on the northern side of the equator in the Atlantic, which suggests a slightly positive AMM index. The AMM, which is reviewed in detail in Kossin and Vimont (2007), is a measure of the leading mode of coupled air-sea variability in the Atlantic Ocean. Similarly, ENSO is the leading coupled mode in the Pacific Ocean and affects regional Atlantic climate via teleconnections 


\section{SST anomaly $(\sigma)$}

\section{Cluster 1}

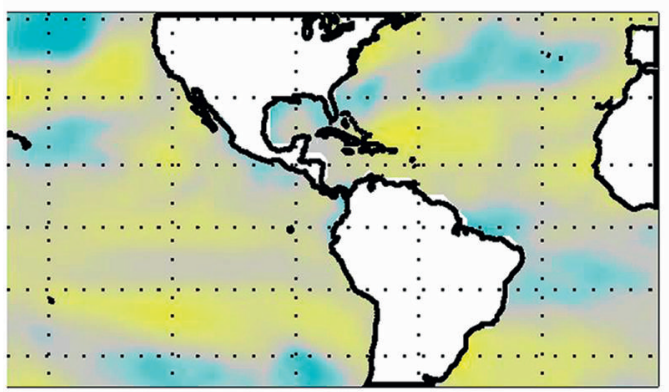

$-0.2$

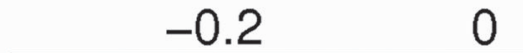

Cluster 3

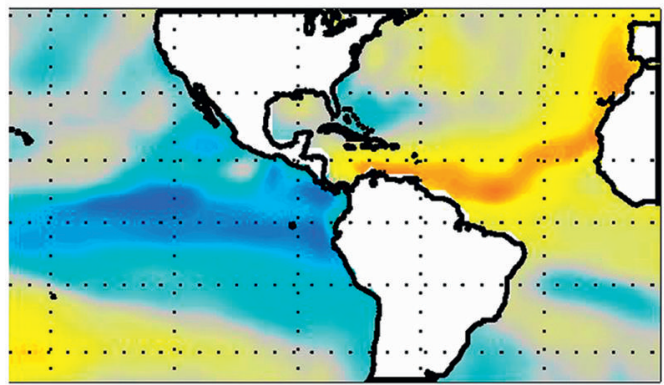

Cluster 2

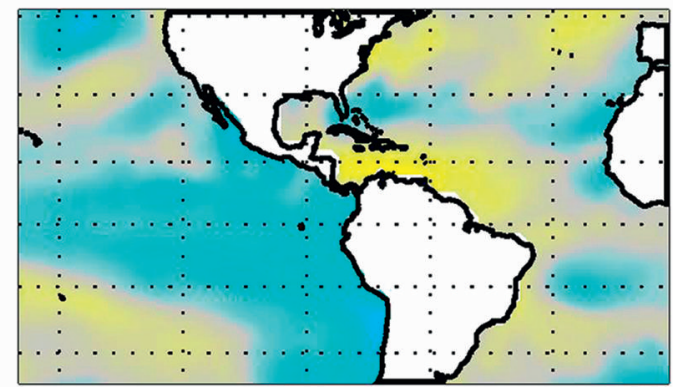

0.4

FIG. 9. Composites of monthly SST anomalies based on cluster membership. Each composite member represents the SST for the month and year of each genesis event. The anomalies are standardized by month and location.

(e.g., Alexander et al. 2002 and references therein). The slow variation of the AMM reflects the decadal variability that is generally described by the Atlantic multidecadal oscillation (AMO) (Delworth and Mann 2000; Enfield et al. 2001; Goldenberg et al. 2001), but unlike the AMO, the AMM also comprises interannual variability that is well correlated with all measures of Atlantic hurricane activity (Xie et al. 2005a,b; Vimont and Kossin 2007; Kossin and Vimont 2007). The AMM, which is sometimes referred to as the Atlantic dipole mode, exhibits maximum variability in the boreal spring but still retains substantial variability during the boreal summer Atlantic hurricane season.

The cluster 2 composite in Fig. 9 shows a similarly weak enhancement of the meridional SST gradient in the Atlantic and also indicates weak La Niña conditions, as evidenced by the broad region of weak cool anomalies in the eastern Pacific. Also similar to their cluster 1 counterparts, cluster 2 storms do not preferentially form over anomalously warm SST. This is consistent with the hypothesis that, in addition to surface fluxes, members of these clusters draw energy from the ambient available potential energy in a baroclinic environment and are less reactive to anomalous SST variability.

Compared with the relatively weak-featured SST composites of clusters 1 and 2, the SST composite associated with cluster 3 exhibits a pronounced warm anomaly spanning most of the North Atlantic hurricane development region. In combination with the cool anomaly in the South Atlantic, this pattern describes the positive phase of the AMM, which is related to a northward shift of the Atlantic intertropical convergence zone. A positive AMM is related to significant rainfall variability in the Nordeste region of Brazil (Hastenrath and Heller 1977) and the Sahel region of Africa (Folland et al. 1986; Hastenrath 1990) as well as marked changes in hurricane activity (Xie et al. 2005a,b; Vimont and Kossin 2007; Kossin and Vimont 2007). In particular, the positive phase of the AMM is associated with a southward shift of the tropical cyclogenesis region farther into the deep tropics, which is consistent with the tracks of cluster 3 (Fig. 1).

Also evident in the cluster 3 SST composite is a pronounced cold anomaly in the equatorial eastern Pacific, 
which indicates that cluster 3 storms form preferentially in La Niña conditions. This aligns with the well-known relationship between ENSO and Atlantic hurricane activity (e.g., Gray 1984). Both the AMM and ENSO are significantly correlated with vertical wind shear in the North Atlantic (Gray 1984; Shapiro 1987; Vimont and Kossin 2007; Kossin and Vimont 2007) with warm (positive) AMM and cold (negative) ENSO phases associated with anomalously low shear. When considered together, these two coupled air-sea modes of variability serve as broad indicators of vertical wind shear across the tropical North Atlantic (see e.g., Kossin and Vimont 2007, their Fig. 6). Note that shear is just one aspect of the overarching thermodynamic state of the region that is described by the AMM and ENSO.

Cluster 4 SST anomaly patterns are similar to those associated with cluster 3 storms, with some interesting differences. In particular, the signatures of a positive AMM and La Niña conditions are present, but the cold anomalies in the eastern Pacific are stronger and exhibit a cross-equatorial symmetry. This pattern bears resemblance to the oceanic surface signature of westward traveling upwelling equatorial ocean Rossby waves forced by eastern boundary reflections of equatorial Kelvin waves (Delcroix et al. 1991; du Penhoat et al. 1992; Picaut et al. 1997). It is not clear that this crossequatorial symmetry of eastern Pacific SST anomalies has any physical relevance to Atlantic tropical cyclogenesis or whether it is just an interesting curiosity, but it may identify a preference for cluster 4 genesis during the more mature stages of La Niña events, while cluster 3 genesis more typically occurs during the earlier stages of La Niña conditions (cf. Larkin and Harrison 2002). This aligns with the seasonality of clusters 3 and 4 (Fig. 2), which shows a preference for proportionally greater frequency of cluster 4 storms in the later part of the hurricane season. However, the cross-equatorial symmetry that emerges in the cluster 4 SST composite is difficult to reproduce with randomly generated SST composites based on various combinations of ENSO phase and time of year, and it is not clear that monthly SST fields should well capture the signature of transient oceanic waves. It remains an open question as to why the mean SST anomalies associated with cluster 4 genesis would bring out such a feature.

\section{c. African easterly waves}

In addition to their markedly different landfall patterns, a clear distinction between cluster 3 and 4 storms is the east-west separation of their genesis locations (Fig. 1). Hopsch et al. (2007) and Chen et al. (2008) recently compared African easterly waves (AEWs) forming along the southern and northern flanks of the African easterly jet and the differences in tropical cyclogenesis characteristics associated with these two disparate categories of waves. The AEWs that form along the northern flank of the jet (denoted " $A E W_{n} \mathrm{~s}$ " by Chen et al. 2008) are less effective at initiating cyclogenesis and must generally track farther westward through a favorable environment before developing a closed warm-core circulation and intensifying into a tropical storm. A potential connection between cluster 4 members and $\mathrm{AEW}_{\mathrm{n}} \mathrm{s}$ is supported by composite analyses (not shown) identifying anomalously high low-level humidity and vorticity associated with cluster 4 cyclogenesis, which was shown by Chen et al. (2008) and Hopsch et al. (2010) to be associated with the subset of $\mathrm{AEW}_{\mathrm{n}} \mathrm{s}$ that ultimately participate in tropical cyclogenesis events. This relationship between the African easterly jet and the genesis rates of cluster 3 and 4 storms demonstrates that even mesoscale circulation features can modulate genesis location, which can have a significant effect on hurricane track, duration, and intensity.

\section{d. Model estimation of annual rates}

As expected from previous studies, the composites of SST show that storm frequency variability is systematically controlled by local and remote climate factors, in particular the variability of the AMM and ENSO. When separated by cluster, however, these relationships appear to be more relevant within certain subsets of the full sample of storms. Here we explore this further. As in the previous section, the annual rate of membership for each cluster is modeled as a Poisson process, and here we consider indices that measure variability in the AMM and ENSO as covariates in addition to year.

\section{1) ATLANTIC MERIDiONAL MODE}

Results of the single-variate Poisson regressions are summarized in Fig. 10. Annual rates of membership in clusters 1 and 2 both show increases with increasing AMM, but the relationships are somewhat weak (confidence less than $95 \%$ ). Cluster 3 and 4 storm rates also exhibit increases with increasing AMM, but here the relationships are much more substantial and highly significant, as evidenced by the $p$ values of the regressions. When the seasonal mean (June-November) of standardized monthly AMM anomalies vary between \pm two standard deviations, the expected annual rates of cluster 3 and 4 storms both increase by a factor of about 6 .

\section{2) El NiÑO-SOUTHERN OSCILLATION}

When annual rates are modeled with a measure of ENSO as the single covariate (Fig. 10, bottom panel), cluster 1 rates increase and cluster 2 rates decrease with increasing Niño $1+2$ index (i.e., tending toward El Niño 

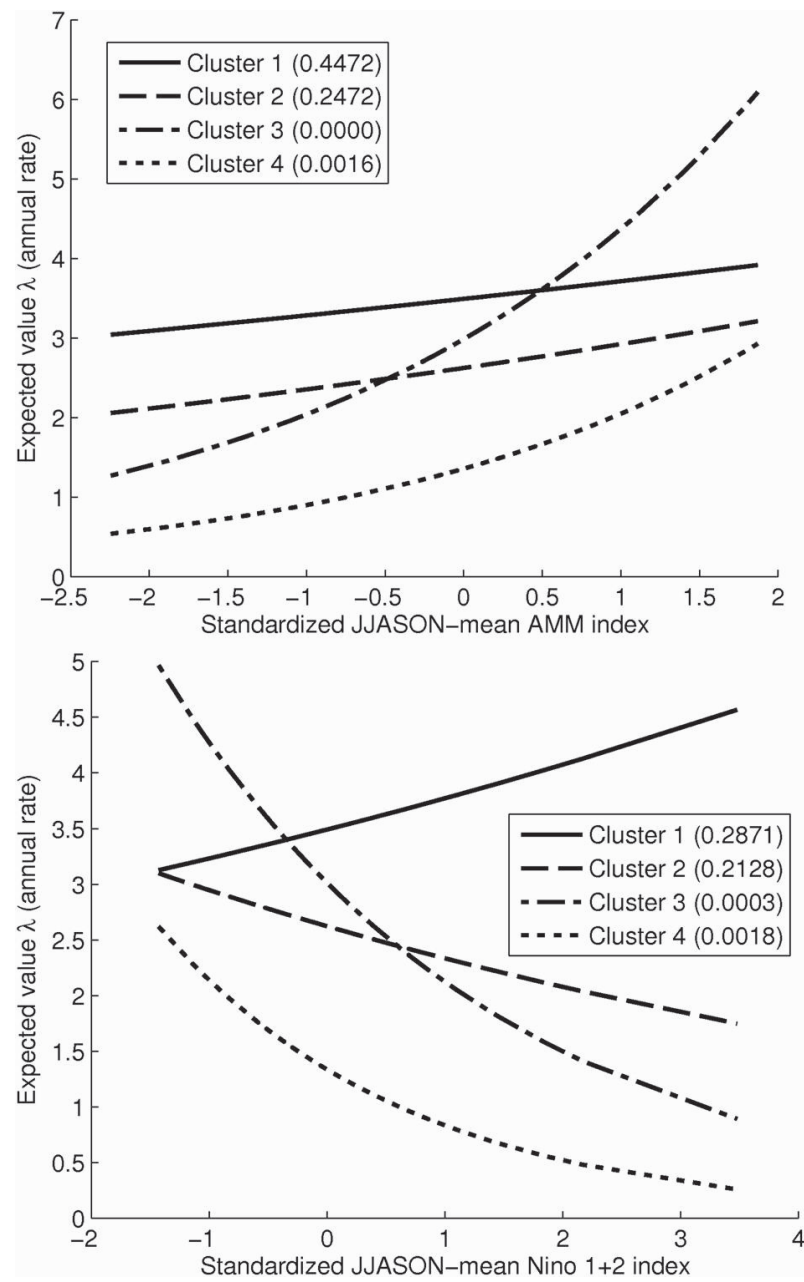

FIG. 10. Expected annual rate, for each cluster, as a function of (top) AMM and (bottom) Niño $1+2$ indices. The indices are based on hurricane season (June-November) means of standardized monthly anomalies. The $p$ value for each regression is shown in parentheses.

conditions), but these relationships have low confidence $(p>0.2)$. Alternatively, the rates of cluster 3 and 4 storms decrease significantly with increasing Niño $1+2$ index. As the seasonal mean of standardized monthly Niño $1+2$ anomalies vary between -1.5 and +3.5 standard deviations, the expected rate of cluster 3 storms increases by a factor of $\sim 5$ and the expected rate of cluster 4 storms increases by a factor of $\sim 6$.

\section{3) Multivariate RATE MOdel}

As a logical next step, we now consider how the rates within each cluster are modulated in combination with both AMM and ENSO. To capture the increasing trend in rates, as discussed in section 3 , time (Year) is included as a third model covariate (the AMM and ENSO indices do not contain significant linear trends over the period
TABLE 4. Poisson regression of annual North Atlantic storm rate (for each cluster) onto the AMM and ENSO indices and year. ENSO is measured with the Niño $1+2$ index. The AMM and ENSO indices are based on June-November means of monthly standardized anomalies. The covariate year is also standardized.

\begin{tabular}{cccc}
\hline \hline & Std & $z$ & $\operatorname{Pr}$ \\
Estimate & error & value & $(>|z|)$ \\
\hline
\end{tabular}

\begin{tabular}{lrrrr} 
& \multicolumn{3}{c}{ Cluster 1 } & \\
(Intercept) & 1.2415 & 0.0710 & 17.50 & 0.0000 \\
AMM & 0.0658 & 0.0817 & 0.80 & 0.4212 \\
Niño 1 + & 0.0860 & 0.0727 & 1.18 & 0.2366 \\
Year & 0.1156 & 0.0710 & 1.63 & 0.1032
\end{tabular}

\begin{tabular}{lrrrr} 
& \multicolumn{3}{c}{ Cluster 2 } & \\
(Intercept) & 0.9614 & 0.0816 & 11.79 & 0.0000 \\
AMM & 0.0902 & 0.0952 & 0.95 & 0.3436 \\
Niño 1 + & -0.1013 & 0.0945 & -1.07 & 0.2839 \\
Year & 0.0074 & 0.0799 & 0.09 & 0.9259
\end{tabular}

\begin{tabular}{lrrrr} 
& \multicolumn{3}{c}{ Cluster 3 } & \\
(Intercept) & 1.0538 & 0.0811 & 13.00 & 0.0000 \\
AMM & 0.3193 & 0.0895 & 3.57 & 0.0004 \\
Niño 1 + & -0.2925 & 0.0971 & -3.01 & 0.0026 \\
Year & 0.1351 & 0.0707 & 1.91 & 0.0562
\end{tabular}

\begin{tabular}{lrrrr} 
& \multicolumn{3}{c}{ Cluster 4 } & \\
(Intercept) & 0.2307 & 0.1249 & 1.85 & 0.0647 \\
AMM & 0.3279 & 0.1331 & 2.46 & 0.0137 \\
Niño 1 + & -0.4088 & 0.1518 & -2.69 & 0.0071 \\
Year & 0.1799 & 0.1048 & 1.72 & 0.0859 \\
\hline
\end{tabular}

1950-2007). The results of the regressions are shown in Table 4. As suggested by the SST composites (Fig. 9), cluster 1 and 2 storm rates exhibit essentially no dependence on these climate covariates. The $p$ values for the AMM and ENSO covariates range from 0.24 to 0.42 and the coefficient estimates are generally near zero. In comparison, the annual rates of cluster 3 and 4 storms are more strongly dependent on the AMM and ENSO as well as year. As expected, rates increase substantially with increasing AMM and decreasing Niño $1+2$ indices.

For each cluster, the model provides an expected rate for each year in the period 1950-2007 based on the annual values of the covariates. The Poisson cumulative distribution functions associated with the 10th and 90th percentiles of these expected rates are shown in Fig. 11. The 10th (90th) percentile expected value is predicted by the model when the environment-as measured by the combined phases of the AMM and ENSO_-is less (more) conducive for cyclogenesis in the deep tropics. For example, when the expected annual rate is at the 10 th percentile, the model assigns only a $1 \%-2 \%$ probability of more than four cluster 3 storms and more than two cluster 4 storms. In comparison, when the expected 

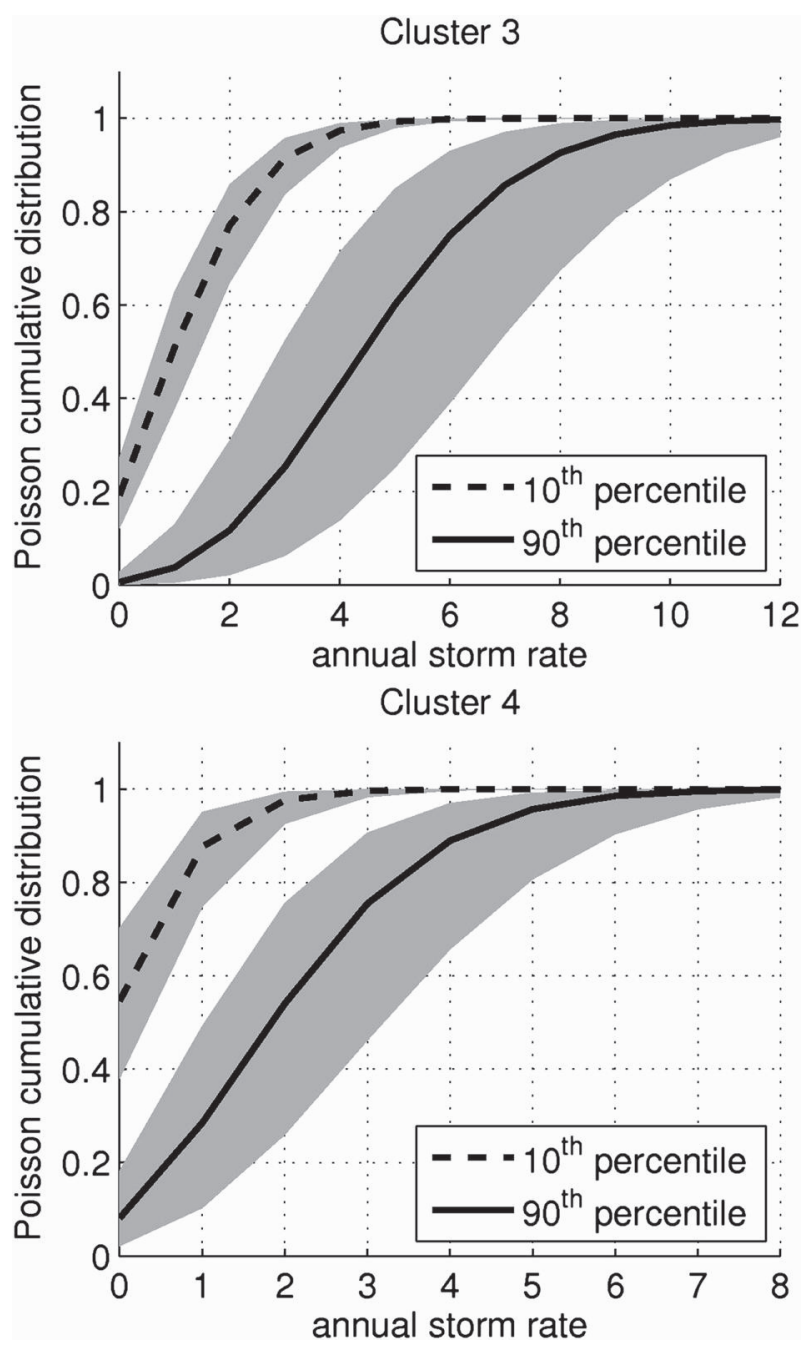

FIG. 11. Cumulative distributions based on the expected values given by the models for clusters 3 and 4 (described in Table 4). The expected values are taken at the 10th and 90th percentile of the 58 values for the years 1950-2007. Shading denotes the region within plus or minus one standard error for the coefficient of each model covariate (given in Table 4).

annual rate is at the 90th percentile, the model assigns a $60 \%$ probability of more than four cluster 3 storms and a $45 \%$ chance of more than two cluster 4 storms.

\section{4) North Atlantic Oscillation}

On the basis of E03, there was an a priori expectation that the phase of the NAO might also relate to cluster membership as defined in the present work. This expectation is based on the assumption of E03 that the boreal late-spring to early-summer NAO projects onto the strength and location of the North Atlantic subtropical high, which in turn modulates the tracks of what E03 termed "straight moving" hurricanes during the forthcoming season. The straight-moving hurricanes of

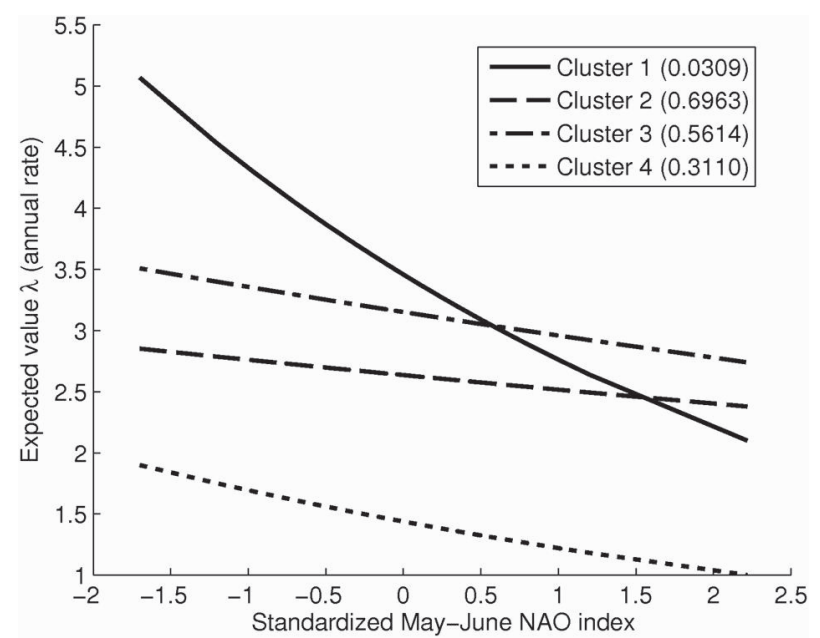

FIG. 12. As in Fig. 10 but for the standardized May-June NAO index.

E03 form a subset of tracks that form in the deep tropics and follow a relatively straight westward trajectory with little or no recurvature. To test this, we considered indices of the NAO as additional potential covariates in our Poisson regression models. Following E03, we tested the May-June averaged NAO index based on sea level pressure difference between Gibraltar and Reykjavik, Iceland (Jones et al. 1997). Since the cluster method and the number of clusters considered here is substantially different from those of E03, and E03 only considered systems of hurricane strength, direct comparisons are not possible. Broad comparisons might be made, however, since the straight-moving group of E03 shares characteristics with our cluster 4 and to a lesser extent with our clusters 1 and 3 .

The NAO index was tested alone and in combination with the other covariates considered above. Within the stated limitations of the comparisons, we did not find relationships with the NAO that are directly analogous to E03, but an interesting signal did emerge. When considered alone, the May-June averaged NAO index relates significantly with the annual rate of our cluster 1 storms (Fig. 12). Congruent with the rate of straightmoving hurricanes of $\mathrm{E} 03$, the rate of cluster 1 storms increases as the NAO tends toward its negative phase. When the May-June mean of standardized monthly NAO anomalies varies between \pm 1.5 standard deviations, the expected annual rate of cluster 1 storms varies significantly by a factor of $\sim 2$.

E03 hypothesized that the May-June NAO index defined by Jones et al. (1997) relates to a persistent shift of the North Atlantic subtropical high toward the southwest, which then maintains tropical North Atlantic easterly steering currents farther to the southwest. 

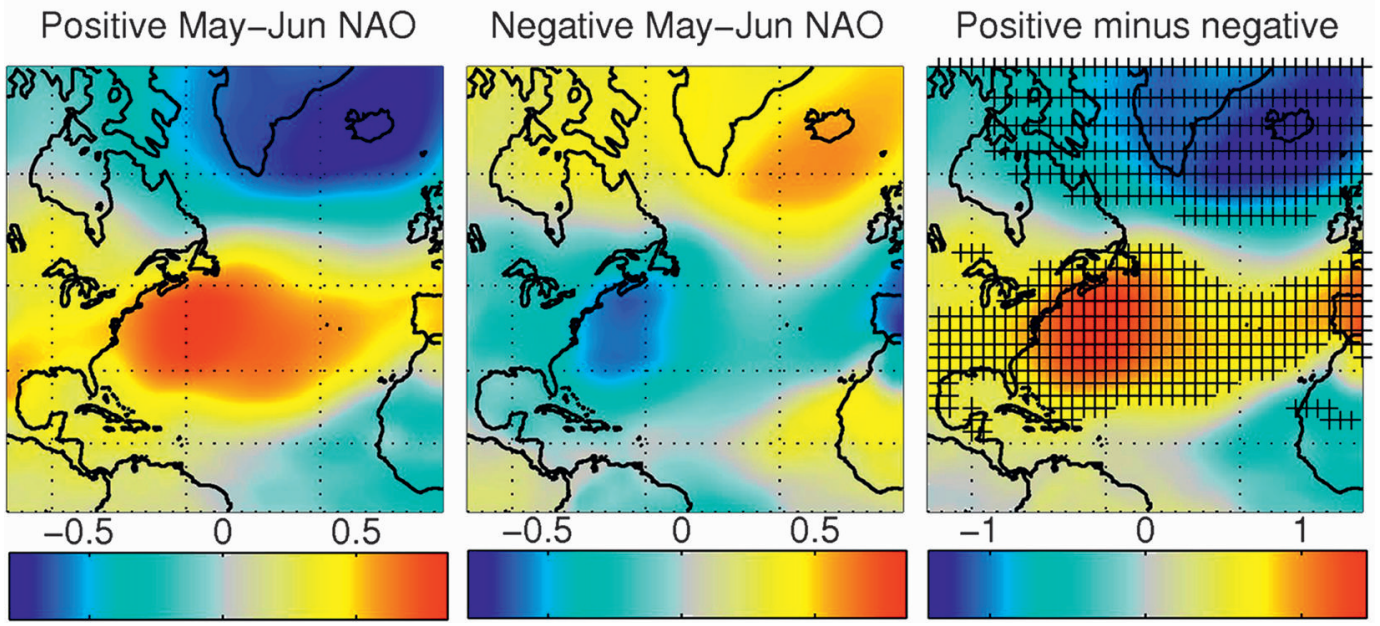

FIG. 13. Composites of May-June mean of standardized SLP anomalies based on the May-June mean NAO index: anomalies are standardized by month and location. Cluster 1 storms are more prevalent during negative NAO phases. Positive and negative NAO composites are based, respectively, on years in the upper and lower quartiles of the 58-yr period 1950-2007. Hatched areas in the difference fields indicate $95 \%$ confidence using a two-sided Student's $t$ test.

Such a shift should reduce the incidence of recurvature, which tends to occur as storms track around the western edge of the high and move into more southerly steering flow. Alternatively, recurvature is often related to the appearance of a "weakness in the ridge," an expression used by hurricane forecasters to describe situations where some portion of the area of high pressure is eroded by other synoptic features. The weakness typically manifests within the western side of the ridge. When this occurs, storms tracking westward along the southern flank of the ridge tend to turn northward through the weakness. To explore this idea further and to help reconcile the statistical relationship identified between cluster 1 storms and the May-June NAO phase, we considered composites of North Atlantic sea level pressure (SLP) anomalies.

The composites of the May-June average of standardized SLP anomalies are shown in Fig. 13. Boreal winter SLP composites on NAO (not shown) naturally display prominent centers of action over Gibraltar and Iceland. These centers of action are weakened and shifted in the boreal spring. In particular, there is a coherent center of action in May-June SLP off the eastern coast of North America, with anomalously low SLP associated with a negative May-June NAO phase. This pattern persists and remains statistically significant when July, August, or September SLP is composited on May-June NAO phase. Thus, when the May-June NAO phase is negative, the western end of the subtropical high is generally weaker throughout most of the hurricane season. This offers a potential explanation for the relationship between cluster 1 storms and NAO phase. When the NAO is negative, the western portion of the ridge is eroded and tracks tend to move northward through the eroded region. The negative SLP anomaly associated with the negative phase of the May-June NAO can also be correlated with locally increased Atlantic tropical cyclogenesis (Ballenzweig 1959; Knaff 1997), which suggests that cluster 1 storms are being regulated by this relationship. It is of historical interest that similar SLP patterns were identified and related to regional differences in Atlantic hurricane activity in the substantive work of Ballenzweig (1959), but no connection was made at that time to the NAO as introduced by Walker and Bliss $(1932,1937)$.

\section{5) MAdDEN-JULiAn OSCILlATion}

The MJO, which is characterized by a 30-60-day oscillation of tropical wind and convection, is also known to modulate tropical cyclone activity globally (e.g., Camargo et al. 2009), and the impact of the MJO on North Atlantic hurricanes has been demonstrated (Maloney and Hartmann 2000; Mo 2000; Klotzbach 2010). Using the Wheeler-Hendon MJO index (Wheeler and Hendon 2004), we counted the tropical storms and hurricanes in each of our clusters during each phase of the MJO index since 1974. Similar to the approach taken in various papers (e.g., Camargo et al. 2009; Vitart 2009), we 

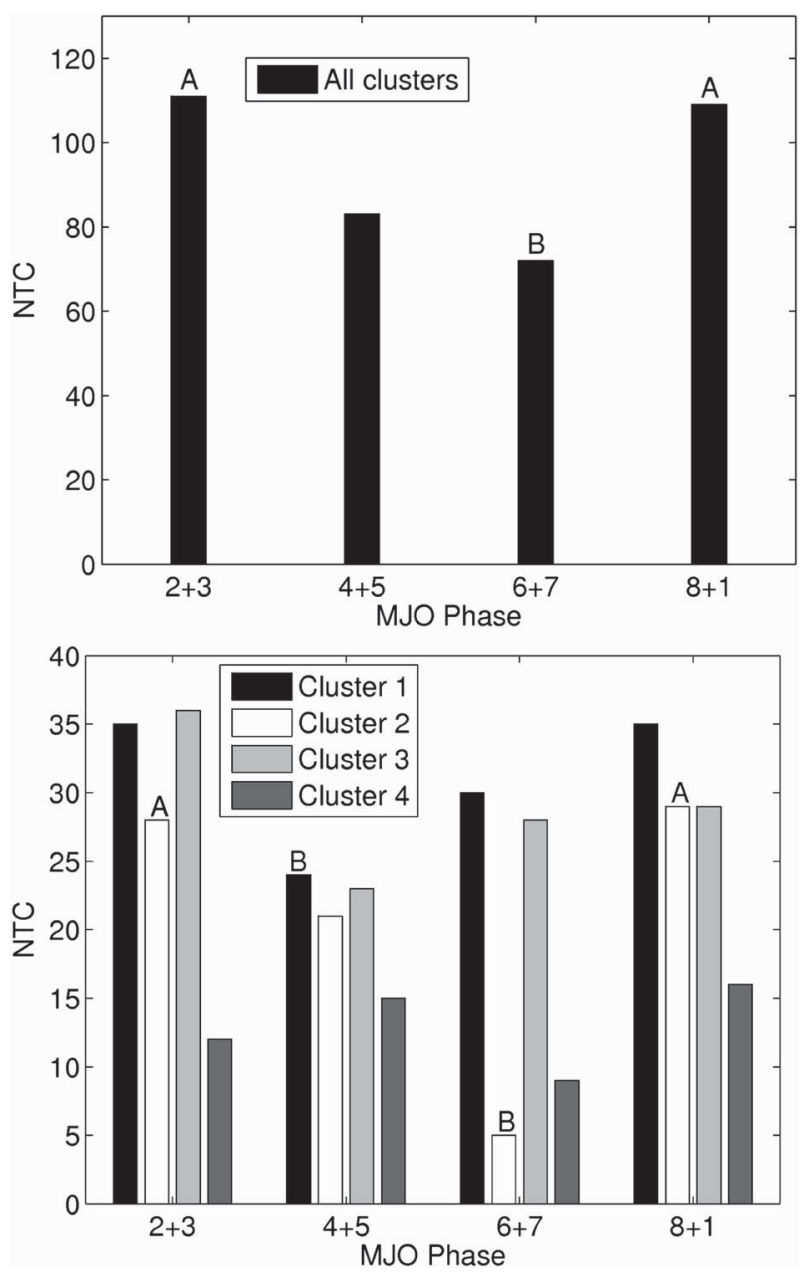

FIG. 14. Number of North Atlantic tropical storms and hurricanes (NTC) within different MJO phases (according to the Wheeler-Hendon index; see definitions in the text) during the period 1974-2007 for (top) all storms and (bottom) storms in each cluster. Statistical significance at the $95 \%$ confidence level above (below) normal is denoted by an A (B) above the bar. Statistic significance was determined using a bootstrap test.

reduced the eight $\mathrm{MJO}$ phases to four phases: an Indian Ocean phase (phases $2+3$ ), a Maritime Continent phase (phases $4+5$ ), a western North Pacific phase (phases $6+7$ ), and a Western Hemisphere phase (phases $8+1$ ). As expected from previous work, North Atlantic storms are modulated by the MJO (Fig. 14a), with a statistically significant above-normal number of storms in phases $2+3$, and $8+1$, and a below-normal number in phase $6+7$. When we repeat this analysis for each of the four clusters, the cluster 2 members (Gulf of Mexico storms) are significantly modulated within the same phases as the whole basin (Fig. 14b), in agreement with Maloney and Hartmann (2000), and a significant reduction of cluster 1 storms is observed in phase $4+5$.

\section{Summary and concluding remarks}

North Atlantic tropical storm and hurricane tracks from 1950 to 2007 were objectively separated into four clusters and analyzed to identify intrabasin variability and trends and their relationships with modes of climate variability. The clusters capture a meridional separation between more tropical systems and their higher-latitude counterparts that interact with a more baroclinic environment. The zonal separation captured by the cluster analysis identifies the subsets of Gulf of Mexico storms and storms spawned within the subset of African easterly waves that form on the northern side of the African easterly jet. Cluster climatologies show differences in seasonality and general characteristics of the storms within each cluster. Marked intercluster differences in storm intensity and longevity, and the proportion and destructiveness of landfalling storms were identified.

In addition to basinwide variability, North Atlantic tropical storms and hurricanes exhibit clear intrabasin differences in frequency and track variability when objectively separated and grouped by clusters. For example, proportions of cluster members exhibit decadal shifts in addition to interannual variability, and these shifts often alternate in sign between clusters. The transition to the present regime of proportionally more tropical and fewer baroclinic systems appears to have begun in the early to mid-1980s, 10 years or more before the very active 1995 Atlantic hurricane season signaled the end of a multidecadal period of quiescence. Additionally, in the period 1950-2007 the steepest positive storm frequency trends are found within the more tropical systems, which comprise more than $70 \%$ of the major hurricanes and overall power dissipation, while Gulf of Mexico storms, which comprise more than $40 \%$ of the total number of landfalling storms, exhibit no trend in this time period.

Intrabasin differences in the relationships between storm and climate variability were also identified and quantified using composite and regression analyses. The tropical cluster members are most strongly modulated by the Atlantic meridional mode (AMM) and El NiñoSouthern Oscillation (ENSO), while the Madden-Julian oscillation (MJO) modulates Gulf of Mexico storms and the North Atlantic Oscillation (NAO) modulates the higher-latitude storms outside of the Gulf of Mexico.

The analyses and models introduced here support the observation that it is not optimal to consider Atlantic tracks as a whole when attempting to quantify the climatic control of tropical cyclogenesis and track (e.g., Elsner et al. 1996). Since storm intensity also depends on genesis location and track, this further suggests that all aspects of hurricane activity are more optimally considered 
after some type of track stratification is performed when identifying trends and associations with climate variability. This should be accounted for when exploring how tropical storms and hurricanes have been responding to climate variability and is a potentially important factor to consider when making future projections of Atlantic hurricane activity. Systematic track changes occurring in response to climate change are expected to affect probability distributions of storm intensity and duration as well as landfall statistics. This adds to the challenge of predicting future activity because it requires that climate models capture systematic changes in regional atmospheric circulation patterns as well as mean thermodynamic state changes.

It is also worth noting that tropical cyclogenesis in the far eastern North Atlantic, which is well described by cluster 3 genesis rates, is sensitive to the strength and location of the African easterly jet (e.g., Bell and Chelliah 2006). Given the very intense, long-lived, and destructive nature of cluster 3 storms, a consequence of this sensitivity is the requirement that climate models not only capture synoptic circulation patterns, but also subtle changes in mesoscale features such as the African easterly jet in order to accurately represent observed hurricane intensity distributions or power dissipation. This requirement is likely to pose challenges even for finer-resolution regional climate models and dynamical downscaling simulations (e.g., Knutson et al. 2008; Bender et al. 2010).

Finally, it should be noted that the separation of tracks provided by our cluster analysis is by no means optimal and only serves as a simple objective method for highlighting intrabasin differences in hurricane variability and links to climatic modes of variability. There is no expectation that the true physical mechanisms modulating hurricane behavior are optimally separated by the method. The cluster analyses presented here are best considered a rough tool for separating tropical storm and hurricane tracks, and caution should be exercised when relating intercluster differences to actual physical mechanisms.

Acknowledgments. We are grateful to Matt Wheeler, Eric DeWeaver, John Molinari, Dave Lorenz, and Dan Vimont for their helpful input, and Kerry Emanuel and two anonymous reviewers for their thoughtful reviews of the original manuscript. This work was funded by the Risk Prediction Initiative of the Bermuda Institute of Ocean Sciences and by NOAA's National Climatic Data Center. SJC acknowledges support from NOAA Grant NA08OAR4320912. The NOAA ERSST V3 data and NCEP-NCAR reanalysis data, and the AMM, Niño $1+2$, and NAO indices were provided by the NOAA/
ESRL Physical Sciences Division, Boulder, Colorado, from their Web site at http://www.esrl.noaa.gov/psd/. The MJO index was obtained from the Center for Australian Weather and Climate Research.

\section{APPENDIX}

\section{Track Clustering Methodology}

The cluster technique builds a mixture of regression models, which are used to fit the geographical shape of historical tropical storm and hurricane tracks (Gaffney et al. 2007). Each component of the mixture model consists of a polynomial regression curve (quadratic in our case) of storm position against time. Finite mixture models enable highly non-Gaussian probability density functions to be expressed as a mixture of a few component probability distribution functions. The model is fit to the data by maximizing the likelihood of the parameters, conditioned on the data. The mixture model easily accommodates tracks of different lengths, contrasting with the $K$-means method used in other studies (e.g., Harr and Elsberry 1995; E03; Elsner and Liu 2003), and can more readily distinguish tracks based on genesis location. Each track is assigned to one of $K$ different regression models, and each model is described by a set of different parameters, regression coefficients and a noise matrix. Recently, Nakamura et al. (2009) applied a new cluster technique based on the mass moments of the tracks to Atlantic hurricanes. In Nakamura et al. (2009) a comparison of applying the $K$-means method, the mixture method, and the moments method for 3 clusters of Atlantic hurricanes is shown. The mixture and the mass moments methods lead to very similar cluster separations.

Similar to the $K$-means method, the number of clusters to be used is not uniquely determined in cluster analysis. As in Camargo et al. (2007b) and Camargo et al. (2008), here we used in-sample log-likelihood values to obtain the optimal choices for the number of clusters. The log likelihood can be interpreted as a goodness-of-fit metric for probabilistic models. Another measure used is the within-cluster spread (difference in latitude and longitude from the mean regression track squared and summed over all tracks in the cluster) for different cluster numbers. As the number of clusters increases, the log-likelihood values increase and the within-cluster spread decreases (Fig. A1). Both curves show diminishing improvement in fit for $K \geq 6$, suggesting a reasonable range of choices of cluster number to be between $K=3$ and 6 , which is very similar to the range obtained for the eastern North Pacific analysis (Camargo et al. 2008). The final selection of the number 


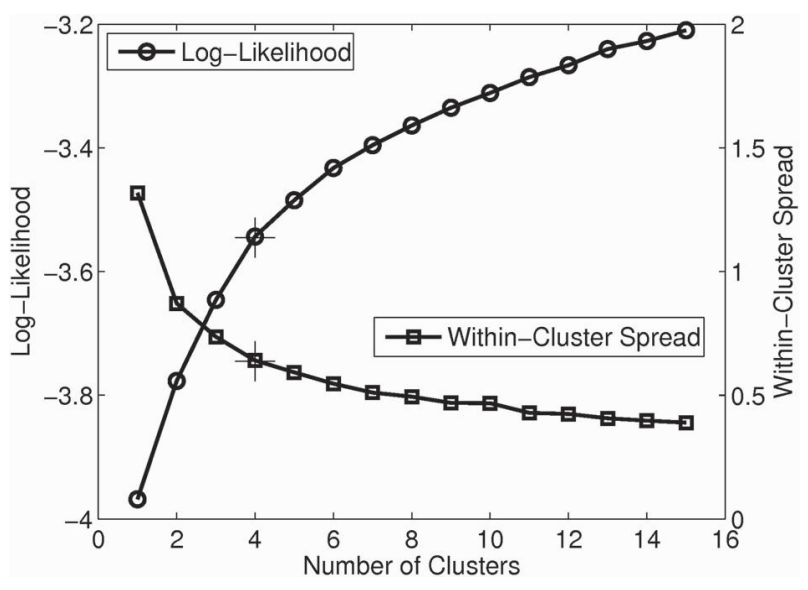

FIG. A1. Log-likelihood values (in sample) and within-cluster spread (difference in latitude and longitude from the mean regression track squared and summed over all tracks in the cluster) for different number of clusters. The + signs mark the values for the four-cluster case used in this work.

of clusters, from $K=3-6$, was qualitatively based on various factors. One was the relationship between tropical storm and hurricane counts and ENSO and AMM indices, which pointed to three or four clusters as the optimal number to explore those relationships. Another selection factor was based on how well the clusters represented subsamples of storm tracks based on geographic location of cyclogenesis (e.g., tropics versus far eastern Atlantic versus Gulf of Mexico). At least four clusters were necessary to describe the track types that appeared in the subsamples explored. Based on these combined factors, the four-cluster case was chosen as optimal in this work.

Similar to Camargo et al. (2008), the stability of the cluster coefficients were examined using a bootstrap method. We performed 100 integrations of the clustering algorithm using subsamples with $50 \%$ of the tracks, drawn at random without replacement. The coefficients of the reference run are always within the interquartile of the distribution and in many cases near the median of the distribution.

\section{REFERENCES}

Alexander, M. A., I. Bladé, M. Newman, J. R. Lanzante, N. C. Lau, and J. D. Scott, 2002: The atmospheric bridge: The influence of ENSO teleconnections on air-sea interaction over the global oceans. J. Climate, 15, 2205-2231.

Ballenzweig, E. M., 1959: Relation of long-period circulation anomalies to tropical storm formation and motion. J. Atmos. Sci., 16, 121-139.

Bell, G. D., and M. Chelliah, 2006: Leading tropical modes associated with interannual and multidecadal fluctuations in North Atlantic hurricane activity. J. Climate, 19, 590-612.
Bender, M. A., T. R. Knutson, R. E. Tuleya, J. J. Sirutis, G. A. Vecchi, S. T. Garner, and I. Held, 2010: Modeled impact of anthropogenic warming on the frequency of intense Atlantic hurricanes. Science, 327, 454-458, doi:10.1126/science.1180568.

Blake, E. S., E. N. Rappaport, and C. W. Landsea, 2007: The deadliest, costliest, and most intense United States tropical cyclones from 1851 to 2006 (and other frequently requested hurricane facts). NOAA Tech. Memo. NWS TPC-5, 43 pp.

Bracken, W. E., and L. F. Bosart, 2000: The role of synoptic-scale flow during tropical cyclogenesis over the North Atlantic Ocean. Mon. Wea. Rev., 128, 353-376.

Camargo, S. J., K. A. Emanuel, and A. H. Sobel, 2007a: Use of a genesis potential index to diagnose ENSO effects on tropical cyclone genesis. J. Climate, 20, 4819-4834.

- A. W. Robertson, S. J. Gaffney, P. Smyth, and M. Ghil, 2007b: Cluster analysis of typhoon tracks. Part I: General properties. J. Climate, 20, 3635-3653.

$-, \ldots,-\frac{1}{-}$, and,$- 2007 \mathrm{c}$ : Cluster analysis of typhoon tracks. Part II: Large-scale circulation and ENSO. J. Climate, 20, 3654-3676.

$\longrightarrow,-$ A. G. Barnston, and M. Ghil, 2008: Clustering of eastern North Pacific tropical cyclone tracks: ENSO and MJO effects. Geochem. Geophys. Geosyst., 9, Q06V05, doi:10.1029/ 2007 GC001861.

_ M. C. Wheeler, and A. H. Sobel, 2009: Diagnosis of the MJO modulation of tropical cyclogenesis using an empirical index. J. Atmos. Sci., 66, 3061-3074.

Chand, S. S., and K. J. E. Walsh, 2009: Tropical cyclone activity in the Fiji region: Spatial patterns and relationship to large-scale circulation. J. Climate, 22, 3877-3893.

$\longrightarrow$, and - 2010: The influence of the Madden-Julian oscillation on tropical cyclone activity in the Fiji region. J. Climate, 23, 868-886.

Chen, T. C., S. Y. Wang, and A. J. Clark, 2008: North Atlantic hurricanes contributed by African easterly waves north and south of the African easterly jet. J. Climate, 21, 6767-6776.

Davis, C. A., and L. F. Bosart, 2003: Baroclinically induced tropical cyclogenesis. Mon. Wea. Rev., 131, 2730-2747.

Delcroix, T., J. Picaut, and G. Eldin, 1991: Equatorial Kelvin and Rossby waves evidenced in the Pacific Ocean through sea level and surface current anomalies. J. Geophys. Res., 96 (Suppl.), 3249-3262.

Delworth, T. L., and M. E. Mann, 2000: Observed and simulated multidecadal variability in the Northern Hemisphere. Climate Dyn., 16, 661-676.

DeMaria, M., J. A. Knaff, and B. H. Conell, 2001: A tropical cyclone genesis parameter for the tropical Atlantic. Wea. Forecasting, 16, 219-233.

du Penhoat, Y., T. Delcroix, and J. Picaut, 1992: Interpretation of Kelvin/Rossby waves in the equatorial Pacific from modelGeosat data intercomparison during the 1986-1987 El Niño. Oceanol. Acta, 15, 545-554.

Elsner, J. B., 2003: Tracking hurricanes. Bull. Amer. Meteor. Soc., 84, 353-356.

— seasonal predictions of intense Atlantic hurricane activity. Wea. Forecasting, 8, 345-351.

— mate and Society. Oxford University Press, 488 pp.

—, and K. B. Liu, 2003: Examining the ENSO-typhoon hypothesis. Climate Res., 25, 43-54.

_ G. S. Lehmiller, and T. B. Kimberlain, 1996: Objective classification of Atlantic hurricanes. J. Climate, 9, 2880-2889. 
Emanuel, K. A., 1986: Air-sea interaction theory for tropical cyclones. Part I: Steady-state maintenance. J. Atmos. Sci., 43, 585-604.

_ 2000: A statistical analysis of tropical cyclone intensity. Mon. Wea. Rev., 128, 1139-1152.

_ 2005: Increasing destructiveness of tropical cyclones over the past 30 years. Nature, 436, 686-688.

- 2010: Tropical cyclone activity downscaled from NOAACIRES reanalysis, 1908-1958. J. Adv. Model. Earth Syst., 2, doi:10.3894/JAMES.2010.2.1.

Enfield, D. B., A. M. Mestas-Nunez, and P. J. Trimble, 2001: The Atlantic multidecadal oscillation and its relation to rainfall and river flows in the continental U.S. Geophys. Res. Lett., 28, 2077-2080.

Folland, C. K., T. N. Palmer, and D. E. Parker, 1986: Sahel rainfall and worldwide sea temperatures, 1901-85. Nature, 320, 602-607.

Gaffney, S. J., A. W. Robertson, P. Smyth, S. J. Camargo, and M. Ghil, 2007: Probabilistic clustering of extratropical cyclones using regression mixture models. Climate Dyn., 29, 423-440.

Goldenberg, S. B., and L. J. Shapiro, 1996: Physical mechanisms for the association of El Niño and West African rainfall with Atlantic major hurricane activity. J. Climate, 9, 1169-1187.

— C. W. Landsea, A. M. Mestas-Nuñez, and W. M. Gray, 2001: The recent increase in Atlantic hurricane activity: Causes and implications. Science, 293, 474-479.

Gray, W. M., 1968: Global view of the origin of tropical disturbances and storms. Mon. Wea. Rev., 96, 669-700.

_ 1984: Atlantic seasonal hurricane frequency. Part I: El Niño and $30 \mathrm{mb}$ quasi-biennial oscillation influences. Mon. Wea. Rev., 112, 1649-1668.

Harr, P. A., and R. L. Elsberry, 1995: Large-scale circulation variability over the tropical western North Pacific. Part I: Spatial patterns and tropical cyclone characteristics. Mon. Wea. Rev., 123, 1225-1246.

Hastenrath, S., 1990: Decadal-scale changes of the circulation in the tropical Atlantic sector associated with Sahel drought. Int. J. Climatol., 10, 459-472.

_ , and L. Heller, 1977: Dynamics of climate hazards in Northeast Brazil. Quart. J. Roy. Meteor. Soc., 103, 77-92.

Hess, J., J. Elsner, and N. LaSeur, 1995: Improving seasonal hurricane predictions for the Atlantic basin. Wea. Forecasting, 10, $425-432$.

Hodanish, S., and W. M. Gray, 1993: An observational analysis of tropical cyclone recurvature. Mon. Wea. Rev., 121, 2665-2689.

Holland, G. J., 1997: The maximum potential intensity of tropical cyclones. J. Atmos. Sci., 54, 2519-2541.

Hopsch, S. B., C. D. Thorncroft, K. Hodges, and A. Aiyyer, 2007: West African storm tracks and their relationship to Atlantic tropical cyclones. J. Climate, 20, 2468-2483.

,,-- and K. R. Tyle, 2010: Analysis of African easterly wave structures and their role in influencing tropical cyclogenesis. Mon. Wea. Rev., in press.

Jarvinen, B. R., C. J. Neumann, and M. A. S. Davis, 1984: A tropical cyclone data tape for the North Atlantic basin, 18861983: Contents, limitations, and uses. NOAA Tech. Memo. NWS NHC 22, 21 pp.

Jones, P. D., T. Jónsson, and D. Wheeler, 1997: Extension to the North Atlantic oscillation using early instrumental pressure observations from Gibraltar and south-west Iceland. Int. J. Climatol., 17, 1433-1450.

Kalnay, E., and Coauthors, 1996: The NCEP/NCAR 40-Year Reanalysis Project. Bull. Amer. Meteor. Soc., 77, 437-471.
Kimberlain, T. B., and J. B. Elsner, 1998: The 1995 and 1996 North Atlantic hurricane seasons: A return of the tropical only hurricane. J. Climate, 11, 2062-2069.

Klotzbach, P. J., 2010: On the Madden-Julian oscillation-Atlantic hurricane relationship. J. Climate, 23, 282-293.

Knaff, J. A., 1997: Implications of summertime sea level pressure anomalies in the tropical Atlantic region. J. Climate, 10, 789-804.

Knutson, T. R., J. J. Sirutis, S. T. Garner, G. A. Vecchi, and I. Held, 2008: Simulated reduction in Atlantic hurricane frequency under twenty-first-century warming conditions. Nat. Geosci., 1, 359-364.

Kossin, J. P., and D. J. Vimont, 2007: A more general framework for understanding Atlantic hurricane variability and trends. Bull. Amer. Meteor. Soc., 88, 1767-1781.

, and S. J. Camargo, 2009: Hurricane track variability and secular potential intensity trends. Climatic Change, 97, 329337, doi:10.1007/s10584-009-9748-2.

Landsea, C. W., 2007: Counting Atlantic tropical cyclones back to 1900. Eos, Trans. Amer. Geophys. Union, 88, doi:10.1029/ 2007EO180001.

—, G. A. Vecchi, L. Bengtsson, and T. R. Knutson, 2010: Impact of duration thresholds on Atlantic tropical cyclone counts. J. Climate, in press.

Larkin, N. K., and D. E. Harrison, 2002: ENSO warm (El Niño) and cold (La Niña) event life cycles: Ocean surface anomaly patterns, their symmetries, asymmetries, and implications. J. Climate, 15, 1118-1140.

Madden, R. A., and P. R. Julian, 1994: Observations of the 4050-day tropical oscillation-A review. Mon. Wea. Rev., 122, $814-837$.

Maloney, E. D., and D. L. Hartmann, 2000: Modulation of hurricane activity in the Gulf of Mexico by the Madden-Julian oscillation. Science, 287, 2002-2004.

McBride, J. L., and R. Zehr, 1981: Observational analysis of tropical cyclone formation. Part II: Comparison of nondeveloping versus developing systems. J. Atmos. Sci., 38, 1132-1151.

McTaggart-Cowan, R., G. D. Deane, L. F. Bosart, C. A. Davis, and T. J. Galarneau, 2008: Climatology of tropical cyclogenesis in the North Atlantic (1948-2004). Mon. Wea. Rev., 136, 12841304.

Mo, K. C., 2000: The association between intraseasonal oscillations and tropical storms in the Atlantic basin. Mon. Wea. Rev., 128, 4097-4107.

Nakamura, J., U. Lall, Y. Kushnir, and S. J. Camargo, 2009: Classifying North Atlantic tropical cyclone tracks by mass moments. J. Climate, 22, 5481-5494.

Nolan, D. S., E. D. Rappin, and K. A. Emanuel, 2007: Tropical cyclogenesis sensitivity to environmental parameters in radiative-convective equilibrium. Quart. J. Roy. Meteor. Soc., 133, 2085-2107.

Picaut, J., F. Masia, and Y. du Penhoat, 1997: An advective-reflective conceptual model for the oscillatory nature of ENSO. Science, 277, 663-666.

Shapiro, L. J., 1987: Month-to-month variability of the Atlantic tropical circulation and its relationship to tropical storm formation. Mon. Wea. Rev., 115, 2598-2614.

Smith, T. M., R. W. Reynolds, T. C. Peterson, and J. Lawrimore, 2008: Improvements to NOAA's historical merged landocean surface temperature analysis (1880-2006). J. Climate, 21, 2283-2296.

Thorncroft, C., and K. Hodges, 2001: African easterly wave variability and its relationship to Atlantic tropical cyclone activity. J. Climate, 14, 1166-1179. 
Vecchi, G. A., and T. R. Knutson, 2008: On estimates of historical North Atlantic tropical cyclone activity. J. Climate, 21, 35803600.

Vickery, P. J., P. F. Skerjl, and L. A. Twisdale, 2000: Simulation of hurricane risk in the U.S. using empirical track model. J. Struct. Eng., 126, 1222-1237.

Vimont, D. J., and J. P. Kossin, 2007: The Atlantic meridional mode and hurricane activity. Geophys. Res. Lett., 34, L07709, doi:10.1029/2007GL029683.

Vitart, F., 2009: Impact of the Madden-Julian oscillation on tropical storms and risk of landfall in the ECMWF forecast system. Geophys. Res. Lett., 36, L15802, doi:10.1029/ 2009GL039089.

Walker, G. T., and E. W. Bliss, 1932: World weather V. Mem. Roy. Meteor. Soc., 4, 53-84.

, and - 1937: World weather VI. Mem. Roy. Meteor. Soc., 4, 119-139.
Webster, P. J., G. J. Holland, J. A. Curry, and H.-R. Chang, 2005: Changes in tropical cyclone number, duration, and intensity in a warming environment. Science, 309, 1844-1846.

Wheeler, M. C., and H. H. Hendon, 2004: An all-season real-time multivariate MJO index: Development of an index for monitoring and prediction. Mon. Wea. Rev., 132, 1917-1932.

Wing, A. A., A. H. Sobel, and S. J. Camargo, 2007: Relationship between the potential and actual intensities of tropical cyclones on interannual time scales. Geophys. Res. Lett., 34, L08810, doi:10.1029/2006GL028581.

Xie, L., T. Yan, and L. J. Pietrafesa, 2005a: The effect of Atlantic sea surface temperature dipole mode on hurricanes: Implications for the 2004 Atlantic hurricane season. Geophys. Res. Lett., 32, L03701, doi:10.1029/2004GL021702.

,,,--- J. M. Morrison, and T. Karl, 2005b: Climatology and interannual variability of North Atlantic hurricane tracks. J. Climate, 18, 5370-5381. 